Sadeghi Marzaleh, A., Nerbano, S., Sebastiani Croce, A., \& Steiger, R. (2018). OSB

sheathed light-frame timber shear walls with strong anchorage subjected to vertical

load, bending moment, and monotonic lateral load. Engineering structures, 173, 787-799. https://doi .org/10.1016/j.engstruct. 2018.05 .044

\title{
1 OSB sheathed light-frame timber shear walls with 2 strong anchorage subjected to vertical load, bending 3 moment, and monotonic lateral load
}

4 Abdollah Sadeghi Marzaleh $^{\text {a) } * \text {, Stella Nerbano }}{ }^{\text {a)}}$, Andrea Sebastiani Croce ${ }^{\text {a) }}$, René Steiger ${ }^{\text {a) }}$

$6{ }^{\text {a) }}$ Empa, Materials Science and Technology, Structural Engineering Research Laboratory,

7 Ueberlandstrasse 129, 8600 Dübendorf, Switzerland

8

$9 *$ Corresponding author:

10 Email: abdola.sadeghimarzaleh@empa.ch

$11 \quad$ Tel.: +4158765 4909

$12 \quad$ Fax.: +41 587656955

13 


\section{$1 \quad$ Abstract}

2 One of the common lateral load resisting systems in multi-story timber buildings in Central

3 Europe are reinforced concrete shear walls. The RC shear walls are not optimal for timber

4 buildings for several reasons such as: (i) the difference in tolerance between concrete and

5 timber construction procedures, (ii) elevated construction time caused by necessary curing of

6 concrete, (iii) moisture of concrete affecting the integrity and mechanical properties of timber,

7 (iv) relatively high shear stiffness resulting in increased forces in seismic design, and (v)

8 eccentricity with regard to applied seismic forces depending on the location of the shear walls.

9 A light-frame timber shear wall (LFTSW) with OSB sheathing stapled to glued-laminated

10 timber framing and strong anchorages has been investigated in this research program to be used

11 as the single lateral load resisting system being located in the perimeter of the building. Results

12 of experiments and numerical calculations showed $20 \%$ and $37 \%$ increases in shear stiffness

13 and shear resistance, respectively, of the investigated LFTSWs in comparison with established

14 LFTSW configurations. In addition to the conventional racking tests, vertical loads and

15 bending moment were applied to the edge studs in order to study their effect on the in-plane

16 behavior of the investigated LFTSWs. A marginal decrease in shear stiffness and shear

17 resistance was observed due to the vertical load and bending moment applied. The decrease

18 was more significant when applying the vertical loads due to the deformation, to which the

19 staples were exposed, before applying the lateral load. Independent from level and combination

20 of internal forces a ductile behavior was observed experimentally on the investigated LFTSWs,

21 where the failure was governed by ductile displacements in the stapled connection between

22 sheathing and framing. 


\section{$1 \quad 1$ Introduction}

2 In many multi-story timber buildings, the lateral load resistance is provided by a combination

3 of timber walls and reinforced concrete (RC) walls, e.g. for forming the elevator shaft and/or

4 the staircase and also for guaranteeing the safe escape in case of fire hazards. As a result of

5 recent developments in fire research related to timber structures, regulations in many countries

6 allow currently to build timber buildings up to 6 or even more stories without RC staircases.

7 This together with the timber construction companies claiming major drawbacks in

8 construction of mixed timber concrete buildings (namely differences in tolerances, elevated

9 construction time caused by necessary curing of concrete, moisture of concrete affecting the

10 integrity and mechanical properties of timber) made designers come to the idea of providing

11 sufficient resistance for lateral loads to multi-story timber buildings exclusively by few but

12 strong light-frame timber shear walls (LFTSW).

13 With regard to the seismic design of multi-story timber buildings, RC shear walls are not

14 optimal because of their comparatively high stiffness, which may make the structure tend to

15 fundamental periods in the plateau range of the acceleration spectrum. If, additionally, RC

16 shear walls are part of staircases and elevator shafts which frequently are located asymmetric in

17 plan, this results in an eccentricity of the seismic forces and, therefore, torsional forces in

18 buildings. In order to address these issues, the concept investigated in a research project,

19 recently carried out in Switzerland, was to provide the required lateral road resistance to

20 multistory timber buildings by a limited number of LFTSWs located in the perimeter of the

21 building. Thus, the very high stiffness of the RC walls and the irregularity of the building in its

22 plan are avoided.

23 In order to reach this goal, the LFTSWs investigated have a specific configuration as opposed

24 to established LFTSWs (Fig. 1). In the established configuration, the bottom rail is connected 
1 to the foundation with a few hold-downs to prevent uplift caused by rocking and to provide

2 certain ductility to the system. In addition, the edge studs are connected to the bottom rail on its

3 top surface. The connections between the framing members behave as hinges. Therefore, under

4 a racking load, the frame has almost zero resistance and is deformed to a parallelogram. To

5 have an optimized solution for both wind and seismic forces, the LFTSWs investigated in the

6 study presented in this paper have been designed to be comparatively stiff. The edge studs have

7 been rigidly connected to the foundation by means of slotted-in steel plate connections with

8 steel dowels. The bottom rail is additionally attached to the foundation using shear connectors

9 (steel angle connected to the bottom rail by means of annular ring nails and to the foundation

10 by means of Hilti anchors of type HAS-TZ) to transfer the shear forces to the foundation. The

11 shear connectors are nailed through the sheathing panel which results in constraining the panels

12 against translation. The top rail is connected to the edge studs by a pair of screws, similar to the

13 established configuration of light-frame timber walls forming a hinged connection. This

14 specific configuration of the investigated LFTSWs makes them exhibit a different in-plane

15 response compared with the established LFTSWs.

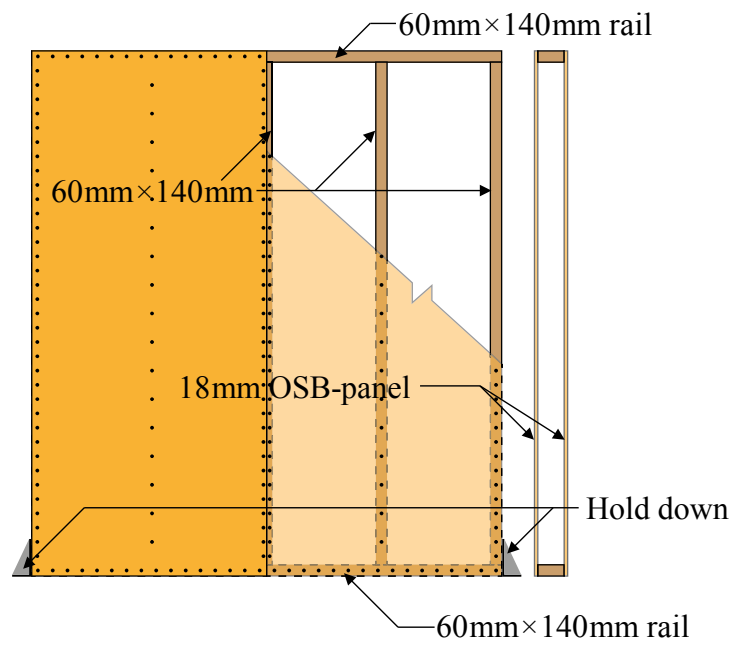

(a)

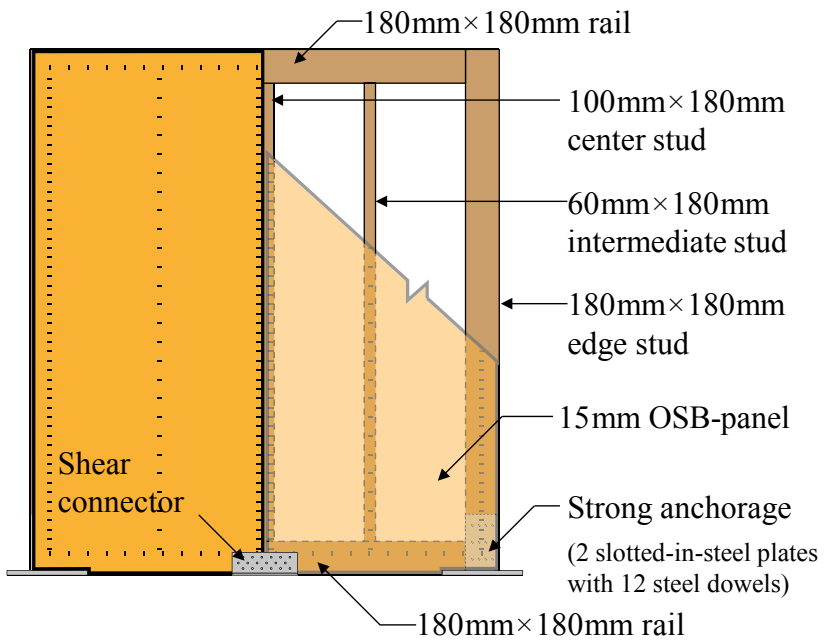

(b)

16 Fig. 1 Configuration and members of (a) established LFTSW (adapted from [1]) and (b)

17 investigated LFTSW in the present study. 
1 Matters of interest when testing timber-framed walls in the recent years were: resistance to

2 combined shear and uplift forces [2], impact of openings ([3], [4], [5]), influence and

3 performance of anchoring and hold down devices [6], influence of boundary conditions and

4 loading protocols ([3], [5], [7], [8], and [9]) and contribution of exterior finishing (e.g. stucco)

5 [10]. Most studies dealt with timber structures for regions of high seismicity. In several

6 countries - due to low-to-moderate seismicity - seismic design requirements do not play the

7 same role. In order to get economic solutions experiments on components of light-frame timber

8 buildings have to reflect this situation with respect to the selection of the appropriate

9 connections and timber elements as well as the relevant loading combination. These issues will

10 affect the structural response at connections, components, and building level and cannot be

11 derived from previous research findings focused on timber structures for regions of high

12 seismicity.

13 In any building, the shear walls located at lower stories beside vertical loads are subjected to

14 bending moment as a result of lateral loads acting on higher stories (mass times ground

15 acceleration). The in-plane response of LFTSWs is assessed experimentally by racking tests

16 e.g. according to ASTM E2126 [11] and ISO 21581 [12] where the wall elements are subjected

17 to a lateral load acting at their top but where the effect of vertical load and bending moment is

18 not investigated. There are studies in which the effect of vertical load on the in-plane response

19 of LFTSWs had been investigated ([13], [14], and [15]). To get a more realistic experiment,

20 however, a bending moment should be applied to the timber shear walls. In an effort to take

21 into account the bending moment, Dujic et al. [3] studied the effect of changes in boundary

22 conditions on the in-plane response of timber shear walls. Their experimental program was

23 focused mainly on the case of partial anchoring of the walls to the foundation where vertical

24 loads hindered the uplift of the walls what finally resulted in an increase of the shear resistance. 
1 To the best of authors' knowledge, there have been no tests in which a bending moment was

2 applied to timber shear walls as a function of lateral load in a controlled way.

3 In the study presented in this paper, a test set-up was designed to apply a combination of

4 vertical load, bending moment, and lateral load to LFTSWs specifically designed to be part of

5 timber-only lateral load resisting shear wall system as described above. The in-plane response

6 of this specific type of LFTSW, here and after named as 'investigated LFTSW', under

7 monotonic lateral loads was investigated and compared with established LFTSWs. The effect

8 of vertical load and bending moment was included in the experimental study and according

9 numerical and analytical models were developed.

\section{Research methodology}

\section{$11 \quad 2.1$ Wall specifications}

12 The global geometry of the LFTSW specimens was kept constant in all tests with length and

13 height equal to $2.5 \mathrm{~m}$ and $2.8 \mathrm{~m}$, respectively. The total wall thickness was $210 \mathrm{~mm}$. The wall

14 element was composed of glued-laminated timber (GLT) GL24h framing [16] and OSB/3

15 sheathing $[17,18]$ on both sides of the wall. Panels of grade OSB/3 are denoted load-bearing

16 panels for use in humid conditions. Based on the product sheets, the implemented OSB/3

17 panels are characterized by elastic moduli of $3800 \mathrm{MPa}$ and $3000 \mathrm{MPa}$ in the main in-plane

18 directions and a shear modulus of $1080 \mathrm{MPa}$. The vertical elements of the framing consisted of

19 two edge studs, a center stud and two intermediate studs with cross-sections of $180 \times 180 \mathrm{~mm}^{2}$,

$20100 \times 180 \mathrm{~mm}^{2}$ and $60 \times 180 \mathrm{~mm}^{2}$, respectively. Top and bottom rails of the frame had a cross-

21 section of $180 \times 180 \mathrm{~mm}^{2}$. The sheathing consisted of two OSB/3 panels with a width of $1.25 \mathrm{~m}$

22 and a thickness of $15 \mathrm{~mm}$ stapled to the both sides of the frame with a spacing of $50 \mathrm{~mm}$ except

23 for the intermediate studs where the spacing was $100 \mathrm{~mm}$. The implemented staples were 
1 characterized by a diameter of $1.53 \mathrm{~mm}$, a crown length of $11.2 \mathrm{~mm}$, a leg length of $55 \mathrm{~mm}$,

2 and an ultimate strength of $f_{u} \geq 600 \mathrm{MPa}$. At each of its corners, the wall was strongly

3 anchored to an RC foundation plate by means of four heavy-duty capsule adhesive

4 Hilti® HVU anchors of diameter M16 and multiple dowelled shear connections with two

5 slotted-in S235 steel plates (Figs. 13 and 15f). Twelve steel dowels of diameter $8 \mathrm{~mm}$ and steel

6 grade $f_{u} \geq 500 \mathrm{MPa}$ were used in these slotted-in connections. The main timber components

7 of the LFTSW are illustrated in Fig. 1. A shear connector was installed at the mid-length of the

8 wall on both sides to contribute in transferring the shear forces to the foundation. It must be

9 mentioned that despite keeping the same global dimensions in all specimens, there was a local

10 but important difference in constructional detailing of the investigated LFTSW at the corners

11 of the walls, where the OSB panels met the steel plates in the anchorage. In one of the tests

12 (HV-WOB) a gap of approximately $2 \mathrm{~cm}$ in width was designed at the mentioned location in

13 order to avoid contact of OSB panels and steel plates similar to the tests performed by Varoglu

14 et al. [19]. This is recommended e.g. by APA [20] in order to prevent premature buckling of

15 the OSB panels (not only in case of seismic action but also to face dimensional changes in the

16 panels due to changes in moisture content of the panels during erection if not adequately

17 acclimatized). Since such procedure often is not the case in practice, the other specimens were

18 produced lacking of a gap between the OSB panels and the steel plates.

\section{$19 \quad 2.2$ Investigations carried out}

20 In this study, first, the methods for estimating the shear stiffness and resistance of light-frame

21 timber shear walls are explained. To have a better estimation of these parameters a finite

22 element (FE) model was developed and verified with the experimental results from the

23 literature. The differences between the investigated and established LFTSWs are described

24 using the FE model. Subsequently, the racking tests, in which vertical load and bending 
moment were applied in addition to the lateral load, are described and the effect of these

2 parameters on the in-plane behavior of investigated LFTSWs are studied. The developed FE

3 model is used for a better explanation of the experimental results. Consequently, some remarks

$4 \quad$ will be provided about the shear stiffness and ductility of the investigated LFTSWs.

5 It is worth mentioning that in the frame of this research project a series of cyclic tests were also

6 performed on investigated LFTSWs that are not reported here for the sake of brevity.

\section{Estimation of shear stiffness and resistance of LFTSW}

\section{$8 \quad 3.1 \quad$ Estimation of stiffness}

9 It is necessary for LFTSWs to satisfy the serviceability limits under wind loads and seismic

10 forces. In case of wind loads, a frequently applied limit is 1/500 of the story height, e.g.

11 Eurocode 5 (EN 1995-1-1) [21] and German standard DIN 1052 [22]). There are many studies

12 available in the literature focusing stiffness evaluation of LFTSWs ([23], [24], [25]). The

13 evaluation of shear stiffness in several standards (e.g. Eurocode 5 (EN 1995-1-1) [21], German

14 standard DIN 1052 [22], Swiss standard SIA 265 [26], Canadian standard CSA O86 [27], and

15 New Zealand standard NZS 3603[28]) has not been addressed in an identical way. Presumably,

16 this is due to various construction types of LFTSWs existing all over the world. In the

17 background document to the German standard DIN 1052, a method has been mentioned for

18 calculating the shear stiffness, which is based on models and experiments by Kessel [29]. In

19 this method, several contributions of deformation under lateral load are summed up and the

20 shear stiffness of the wall is calculated by dividing the lateral load by the total deformation.

21 The final deformed shape and force and stress distribution for calculating these contributions

22 are shown in Fig. 2. The contributions, which are assumed independent, are schematically

23 illustrated in Fig. 3 for a LFTSW composed of only one sheathing panel. 


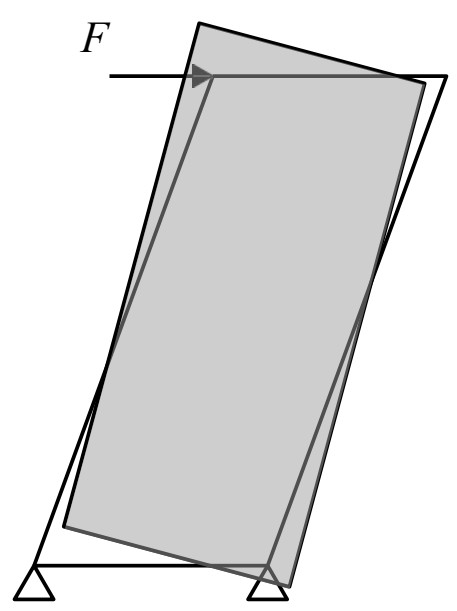

(a)

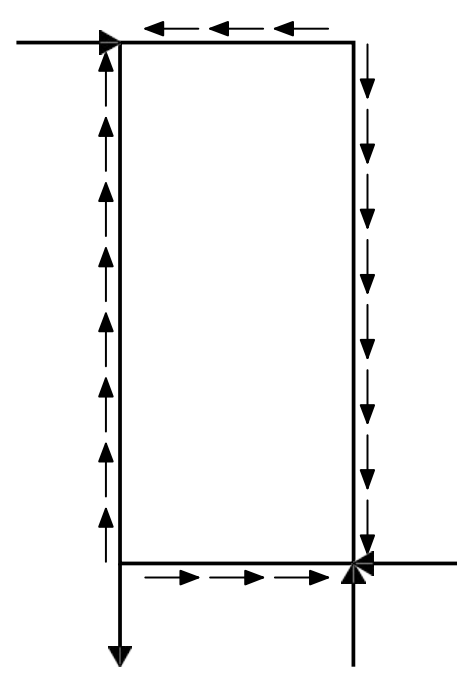

(b)

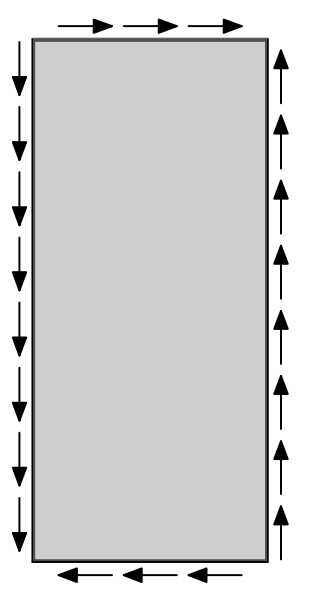

(c)

2 Fig. 2 (a) Deformed shape, (b) stress distribution in framing, and (c) in sheathing panel 3 assumed when calculating the shear stiffness in established LFTSWs [29].

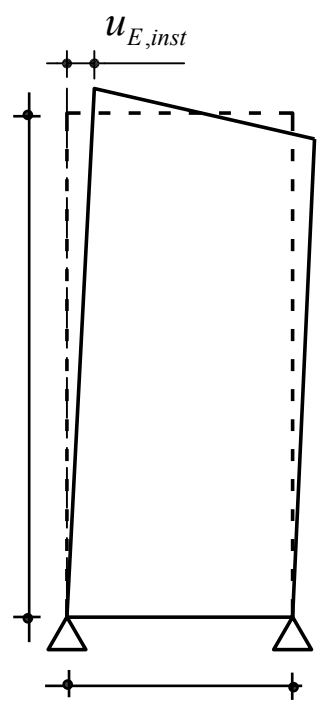

(a)

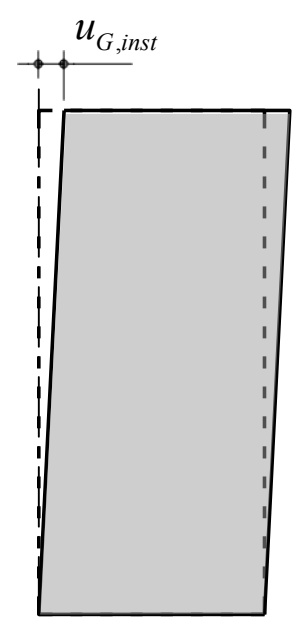

(b)

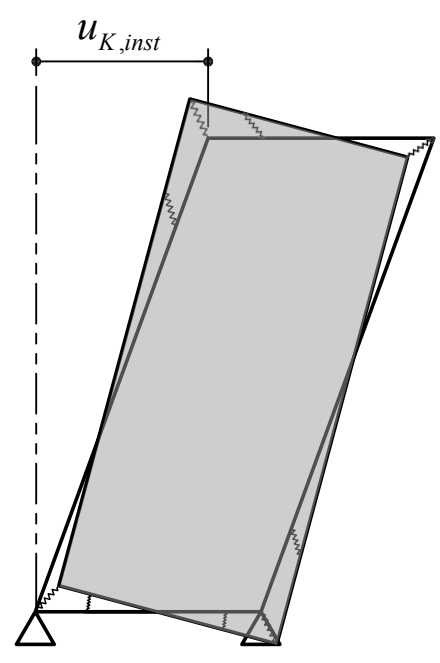

(c)

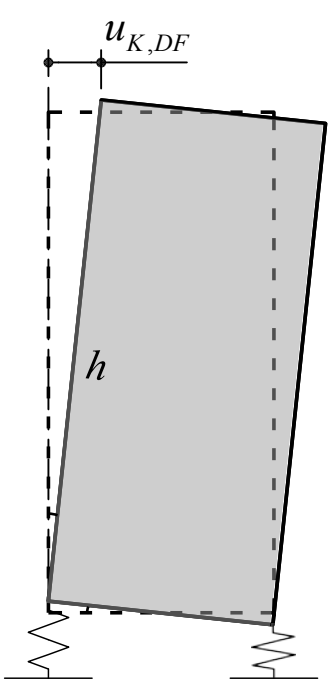

(d)

4 Fig. 3 Partial deformations contributing to the overall horizontal displacement of LFTSWs: (a) framing, (b) sheathing panel, (c) fasteners, and (d) anchorages.

6

7 This method, although not accounting for the interaction between the different deformation

8 components, is implemented here in order to get a first estimate of the shear stiffness of the

9 investigated LFTSW. For that purpose, the following summands contributing to the overall

10 deformation of the LFTSW were taken into account: 
1 (i) Slip of staple with a spacing of $a_{v}$ connecting sheathing to framing:

$$
u_{K, \text { inst }}=\frac{2}{m} \cdot\left[\left(1+n_{h}\right) \cdot l+\left(1+n_{v}\right) \cdot h\right] \frac{F \cdot a_{v}}{K_{s e r} \cdot l^{2}}
$$

2 (ii) Shear deformation of the sheathing panels:

$$
u_{G, i n s t}=\frac{1}{m} \frac{F \cdot h}{G \cdot A^{*}}
$$

3 (iii) Axial deformation of top rails and edge studs:

$$
u_{E, \text { inst }}=\frac{2}{3} \frac{F}{E A}\left(l+\frac{h^{3}}{l^{2}}\right)
$$

4 where $m$ stands for $m$-sided sheathing in LFTSWs ( $m=1$ for one sided and $m=2$ for two-

5 sided), $n_{h}$ and $n_{v}$ for the number of horizontal and vertical joints in the sheathing panels,

6 respectively, and $l$ and $h$ for the length and height of the wall, respectively. The slip modulus

7 of fasteners in the serviceability state is represented by $K_{\text {ser }}$. For the sheathing panel the shear

8 modulus and cross-sectional area have been defined with $G$ and $A^{*}$, respectively. The product

9 of the modulus of elasticity and the cross-sectional area $(E A)$ represents the axial stiffness of

10 the framing members.

11 In addition to the aforementioned deformations, the deformation of anchorages was also taken

12 into consideration using the following formula:

$$
u_{K, D F}=h \cdot \sin \left(\frac{F \cdot h}{K_{D F}}\right)
$$

13 where:

$$
K_{D F}=\frac{1}{2} l^{2} \cdot K_{s e r}
$$


1 Here, the parameter $K_{\text {ser }}$ stands for the elastic slip modulus of the dowels in the slotted-in steel

2 plates anchorages of the wall to the foundation in the serviceability state. The parameter $K_{D F}$

3 represents the rotational stiffness of the wall-to-foundation connection.

4 The slip moduli of staples and anchorage were estimated according to the Swiss standard

5 SIA 265 [26]. The empirical equation (6) expresses the slip modulus of a single shear timber

6 connection with a one-leg staple. For dowels, similarly, equation (7) provides the slip modulus

7 for a single shear timber-steel connection. Hence, for the staple connection and anchorage in

8 this study, the slip moduli have been calculated as $247 \frac{\mathrm{N}}{\mathrm{mm}}$ and $193 \times 10^{3} \frac{\mathrm{N}}{\mathrm{mm}}$, respectively.

$K_{\text {ser }}=60 d^{1.7}$

$K_{\text {ser }}=60 \rho^{0.5} \cdot d^{1.7}$

10 Entering the geometrical and material properties of the investigated wall, the contribution of

11 each deformation was estimated. Fig. 4 shows these contributions in the case of calculating a

12 top wall lateral displacement of $5 \mathrm{~mm}$ equal to the serviceability limit and highlights the

13 predominant contribution of the staples. Using this method, the shear stiffness of the

14 investigated LFTSW was calculated as $3.0 \frac{\mathrm{kN}}{\mathrm{mm}}$.

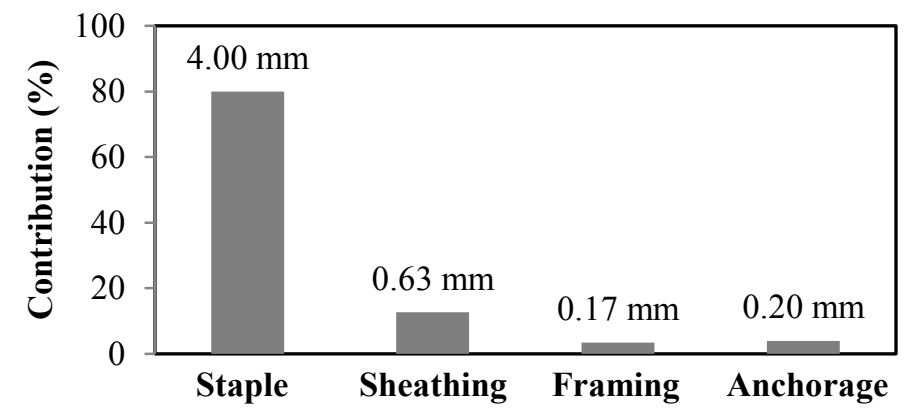

15 Fig. 4 Contribution of partial deformations to a $5 \mathrm{~mm}$ horizontal displacement applied to the 16 top of the investigated LFTSW. 


\section{$1 \quad 3.2$ Estimation of shear strength}

2 The LFTSWs subjected to experiments had been designed according to the German standard

3 DIN 1052:2008 [22]. Based on the standard, the horizontal displacement of the wall top was

4 limited to $\frac{h}{500}=5 \mathrm{~mm}$ for a wind load of $H=20 \mathrm{kN}$. Correspondingly, a series of verifications

5 was conducted for the shear strength of the stapled sheathing to framing connection and of the

6 sheathing panels as well as the resistance of the sheathing panels against buckling for the

7 ultimate limit states. The partial safety factors were taken as $\gamma_{M}=1.0$ and $\gamma_{M}=1.3$ for

8 verification of serviceability and ultimate limit states, respectively. The effects of duration of

9 load and moisture content (EN 1995-1-1 [21]) were considered by applying factors $k_{\text {mod }}=0.9$

10 for wind (i.e. short-term load and service class 1 (EN 1995-1-1 [21])) and $k_{\bmod }=1.1$ for

11 seismic action (i.e. instantaneous load and service class 1). The weakest link was assigned to

12 the sheathing to framing connection $\left(R_{d, \text { Staple }}=347 \mathrm{~N}, f_{v, 0, d, \text { Staple }}=6.9 \frac{\mathrm{kN}}{\mathrm{m}}\right)$ resulting in a design

13 horizontal force of $P_{d}=34.5 \mathrm{kN}$.

\section{$14 \quad 3.3 \quad$ Finite element model}

15 In the analytical model, equations (1) - (4), it is assumed that the center of rotation of the

16 sheathing panels is on their centroid, which is not valid for the investigated LFTSWs because

17 of the constraint of the shear connector. Moreover, the deformation contributions are

18 considered to be uncoupled. In order to have a more realistic evaluation of the shear response

19 of the investigated LFTSWs, a two dimensional FE model (Fig. 5) was developed using

20 Abaqus ${ }^{\circledR}$ taking into account the deformations explained above and their interaction. The

21 model was calibrated with experimental and numerical results from the literature [30] and is

22 used for a better explanation of the experimental results. 


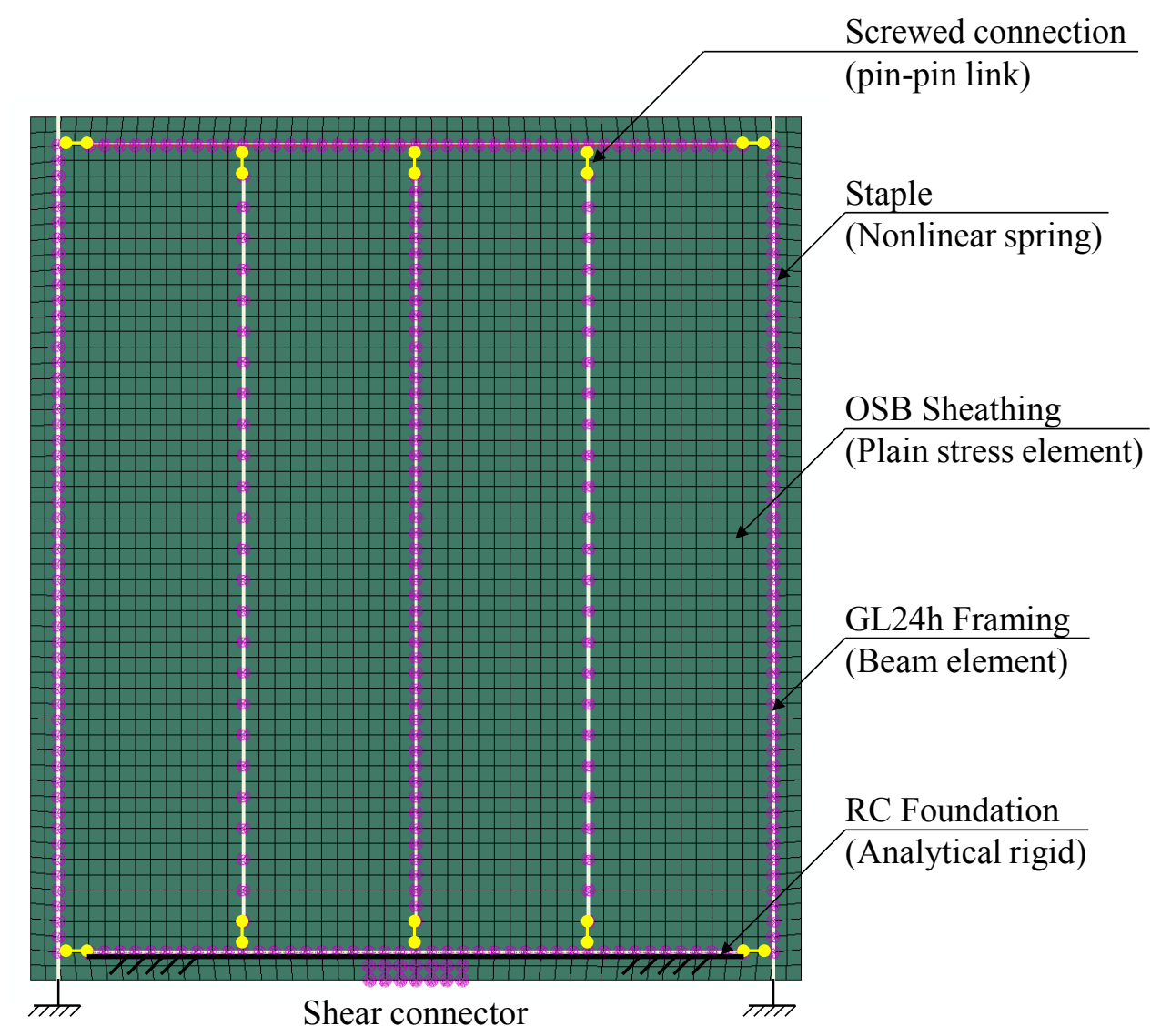

1 Fig. 5 Finite element model of the investigated LFTSW.

3 The framing and sheathing members were modelled using beam and plain stress elements,

4 respectively. Because the model is two dimensional, only one sheathing panel was considered

5 but with a thickness factor of 2. Linear-elastic material behavior was assigned to both elements

6 with modulus of elasticity of 11'000 MPa and 2'600 MPa for the framing and sheathing

7 members, respectively. A Poisson's ratio of 0.2 was considered for both materials. The staples

8 were modeled as nonlinear springs. Each spring in the model represented two staples in the

9 walls connecting the sheathing panels to both sides of the framing. Since a large-deformation

10 analysis was performed, the orientation of springs has been updated in the incremental analysis

11 and therefore the springs can be considered as a single oriented spring. In the analyses of the

12 LFTSW, the orientation of the oriented springs changes according to the lateral displacement

13 applied to the top of the wall and the relative displacement of the framing and sheathing panels. 
1 At the end of each increment, the final state of the wall is taken into account to find the

2 elongation of the springs and their orientation. Accordingly, the force generated in the staples

3 is applied to both framing and sheathing panels in an opposite direction and the equilibrium

4 equation is satisfied for the LFTSW.

5 The monotonic behavior of stapled OSB sheathing to glulam framing connections was studied

6 in an accompanying module of the project [31] in a series of tests using a tensile testing

7 machine subjecting the stapled connection to shear. The nonlinear behavior of the staples taken

8 from the results of these tests and used in the FE model is shown in Fig. 6b. Properties

9 assigned to the springs were based on the mean value curve. It must be mentioned that the

10 behavior of a single staple was extracted from the test results performed on samples with

11 different number of staples by taking an average.

12 The two main differences of the investigated LFTSW compared with established LFTSW were

13 also considered in the numerical model; (i) the edge studs were rigidly connected to the

14 foundation and (ii) the shear connector constrained the movement of the OSB sheathing panels.

15 The former was considered in the model because of comparatively less significant contribution

16 of anchorage in total deformation of the LFTSWs investigated in this study. To address the

17 latter, the shear connector was modeled by assigning rigid links from the fixed foundation to

18 the nodes of sheathing panels that are in contact with the shear connector.

19 In a first step the LFTSW was modelled without considering theses effects, resulting in a

20 behavior similar to that of established LFTSWs and offering the possibility to verify the model

21 with experimental results and numerical models published in the literature. The FE model was

22 verified with the commonly referred example in CASHEW[32]. Besides the necessary changes

23 in the geometry, the shear versus slip behavior of the staples was modified and taken from Fig.

24 6a. As shown in Fig. 7a, a good agreement was found between the developed model, the

25 CASHEW model and experimental results presented in [32]. 


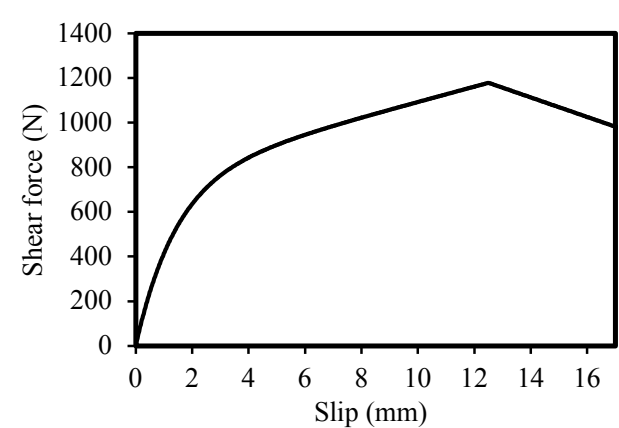

(a)

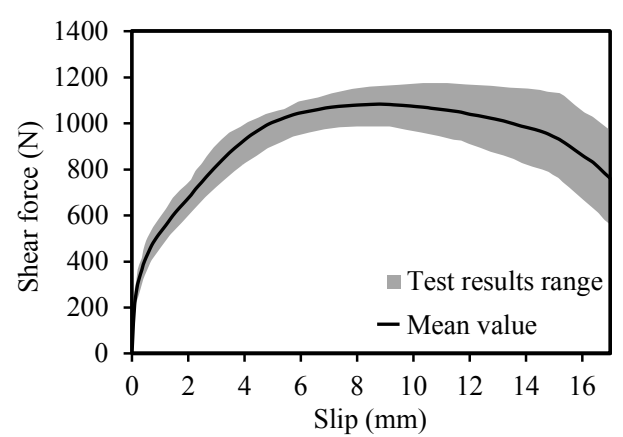

(b)

1 Fig. 6 Monotonic nonlinear behavior of one single staple (a) considered in the CASHEW

2 example [30] and (b) obtained from experiments [31].

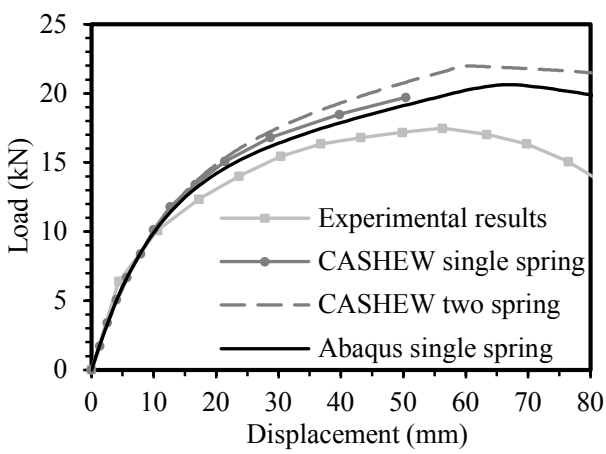

(a)

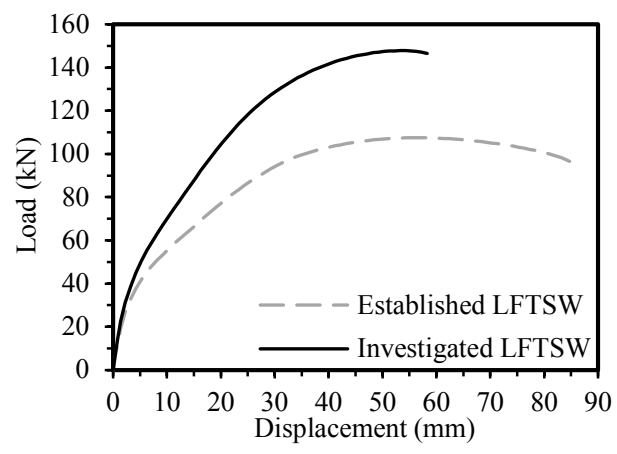

(b)

$4 \quad$ Fig. 7 (a) Verification of the Abaqus ${ }^{\circledR}$ FE model with CASHEW exemplary calculation and 5 experimental results [30]. (b) In-plane lateral load - displacement behavior of investigated 6 LFTSWs with strong anchorage in comparison with established LFTSWs.

8 Fig. 7b compares the in-plane response of the LFTSWs investigated in this study with that of

9 established walls. The curves are drawn until the first staple reaches its maximum slip, which is

10 equal to $17 \mathrm{~mm}$ as has been found in the accompanying experiments on connections [31] (Fig.

11 6b). According to the results of the FE calculations, the investigated LFTSW, considering a

$125 \mathrm{~mm}$ horizontal displacement at the top of the wall (equal to $1 / 500$ of the story height [22]) as

13 serviceability limit state, showed a $20 \%$ higher shear stiffness compared with the established

14 LFTSW. The shear resistance of the investigated LFTSW was 37\% higher than that of the 15 established LFTSW. 


\section{Experimental study}

\section{$2 \quad 4.1$ Test program}

3 Three large-scale wall tests were conducted to investigate the in-plane monotonic behavior of

4 the LFTSWs when subjected to simultaneously acting bending moment and vertical load

5 (Table 1). The naming of specimens was based on the level of vertical load (L: low and H:

6 high) and weather a bending moment was applied (WB) or not (WOB).

7 Table 1: Test program under various actions: distributed vertical load $(N)$, concentrated vertical

8 loads $\left(F_{1}\right.$ and $\left.F_{2}\right)$, lateral load $(P)$, and bending moment $(M)$.

\begin{tabular}{|c|c|c|c|c|}
\hline \multirow{3}{*}{ Test } & \multicolumn{2}{|c|}{ Vertical loads } & \multirow{3}{*}{$\begin{array}{l}\text { Lateral loading protocol } \\
\qquad P\end{array}$} & \multirow{3}{*}{$\begin{array}{l}\text { Bending moment / lateral load ratio } \\
\qquad \frac{M}{P \cdot h}\end{array}$} \\
\hline & $N$ & $F_{1}=F_{2}{ }^{b)}$ & & \\
\hline & $(\mathrm{kN})$ & $(\mathrm{kN})$ & & \\
\hline LV-WOB & & 15 & & 0 \\
\hline HV-WOB & $60^{\mathrm{a})}$ & 123 & ISO 21581 [12], monotonic & 0 \\
\hline LV-WB & & 15 & & 0.4 \\
\hline
\end{tabular}

12 To investigate the effect of vertical load, two tests were designed with different load levels and

13 without bending moment. To have a more realistic representation of the load transfer in a

14 timber building, two different vertical loads were considered including a distributed vertical

15 load and a pair of concentrated ones that, respectively, represent the permanent load of the

16 story located right on top of the wall $(N)$ and that of the rest of stories located above the wall

$17\left(F_{1}\right.$ and $\left.F_{2}\right)$. The distributed vertical load $N$ is introduced into the top rail, whereas the

18 concentrated ones are applied to the edge studs. The reference wall, namely LV-WOB, was

19 designed to be tested under a low concentrated vertical load representing the stress state of a 
1 shear wall located in the second floor of a typical three-story residential or office timber

2 building in Switzerland consisting of timber concrete composite (TCC) slabs with spans

3 between $4 \mathrm{~m}$ (residential building) and $8 \mathrm{~m}$ (office building). For more information about the

4 constructional details of such type of buildings, the reader is referred to Steiger et al. [33]. The

5 test under high concentrated vertical load, HV-WOB, was designed to represent a wall located

6 in the ground floor of the three-story building, but carrying the load of a wider span slab.

7 The bending moment was applied in the test LV-WB, in which the vertical load was equivalent

8 to the test LV-WOB. The bending moment was evaluated based on the location of the wall

9 being in the second story of the 3-story building (Fig. 8). The shear force distribution was

10 calculated based on the assumption of equal mass in all story levels except the top story, in

11 which half of the mass of other stories was assigned. In addition to the shear force, a respective

12 bending moment is acting on each story. Based on the assumed location of the wall in height,

13 only the concentrated lateral load at the roof level applies a bending moment to the wall. The

14 ratio of bending moment to shear force in story 2 was evaluated as 0.4 . The bending moment

15 was replaced by a set of coupled vertical loads and applied by servo-hydraulic actuators to the

16 walls; therefore, in the test LV-WB, the compressive vertical load in the cylinders applying the

17 bending moment read $F_{1}=15-0.4 P \frac{h}{d}$ and $F_{2}=15+0.4 P \frac{h}{d}$. 

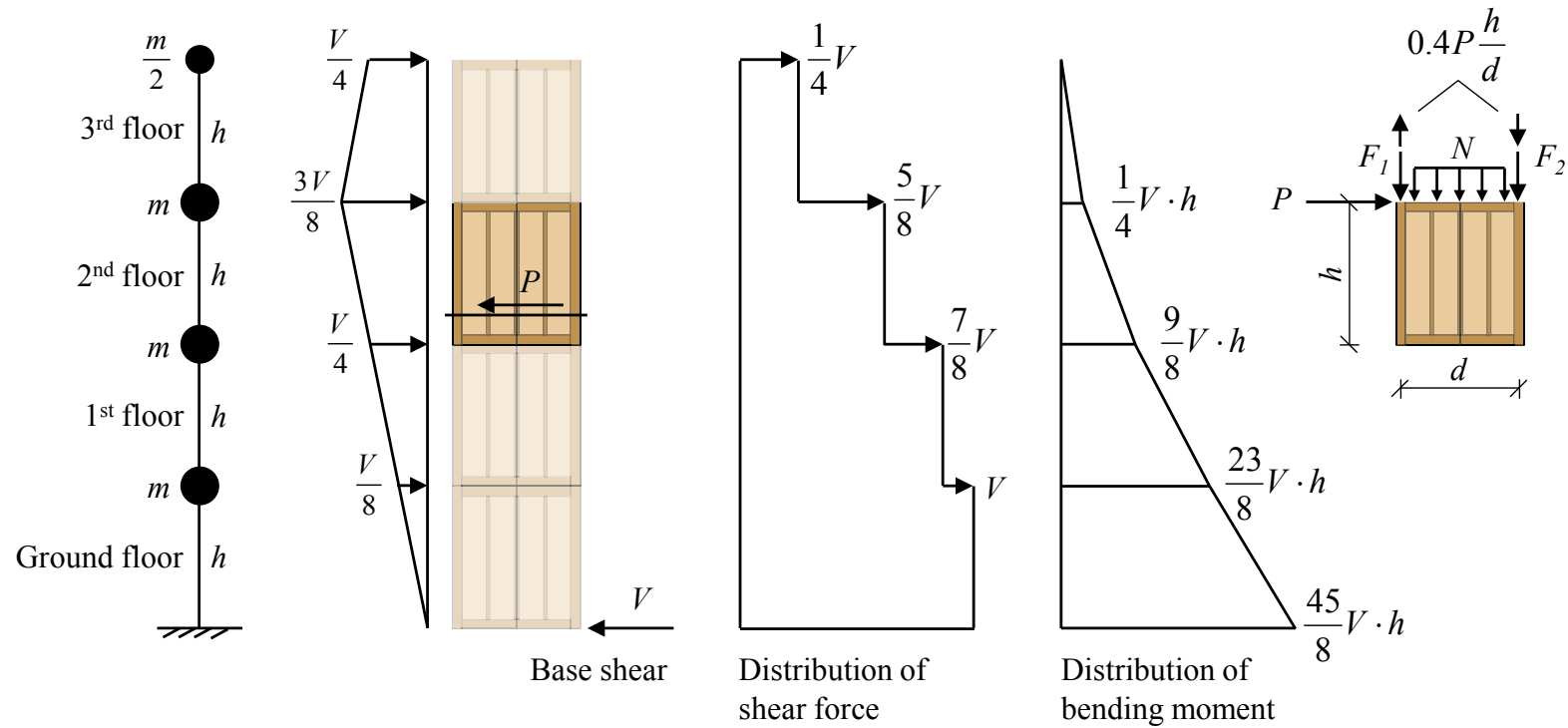

1 Fig. 8 Distribution of vertical load, shear force, and bending moment along the height of the

2 shear wall and the actions on a LFTSW located in the 2 nd floor of a multi-story building.

\section{$3 \quad 4.2$ Test setup}

4 Fig. 9 shows the main components of the test setup. A rigid reaction frame and a concrete

5 foundation were set up on the strong floor. Two hydraulic cylinders and two servo-hydraulic

6 actuators were installed vertically to the reaction frame in order to apply the vertical loads to

7 the LFTSW specimens. The hydraulic cylinders were considered to apply the distributed

8 vertical load $N$ explained above. The vertical servo-hydraulic actuators applied concentrated

9 vertical loads as well as bending moment $\left(F_{1}\right.$ and $\left.F_{2}\right)$. The bending moment was generated by

10 applying unequal vertical loads in the vertical servo-hydraulic actuators. A servo-hydraulic

11 actuator was connected horizontally to the rigid wall to provide the lateral load $P$ applied to

12 the wall. The servo-hydraulic actuators were operated by means of a Digital 3-Channel Control

13 System PCS 8000. A detailed representation of the test components used for introducing the

14 loads and stabilizing the specimen is shown in Fig. 10. 


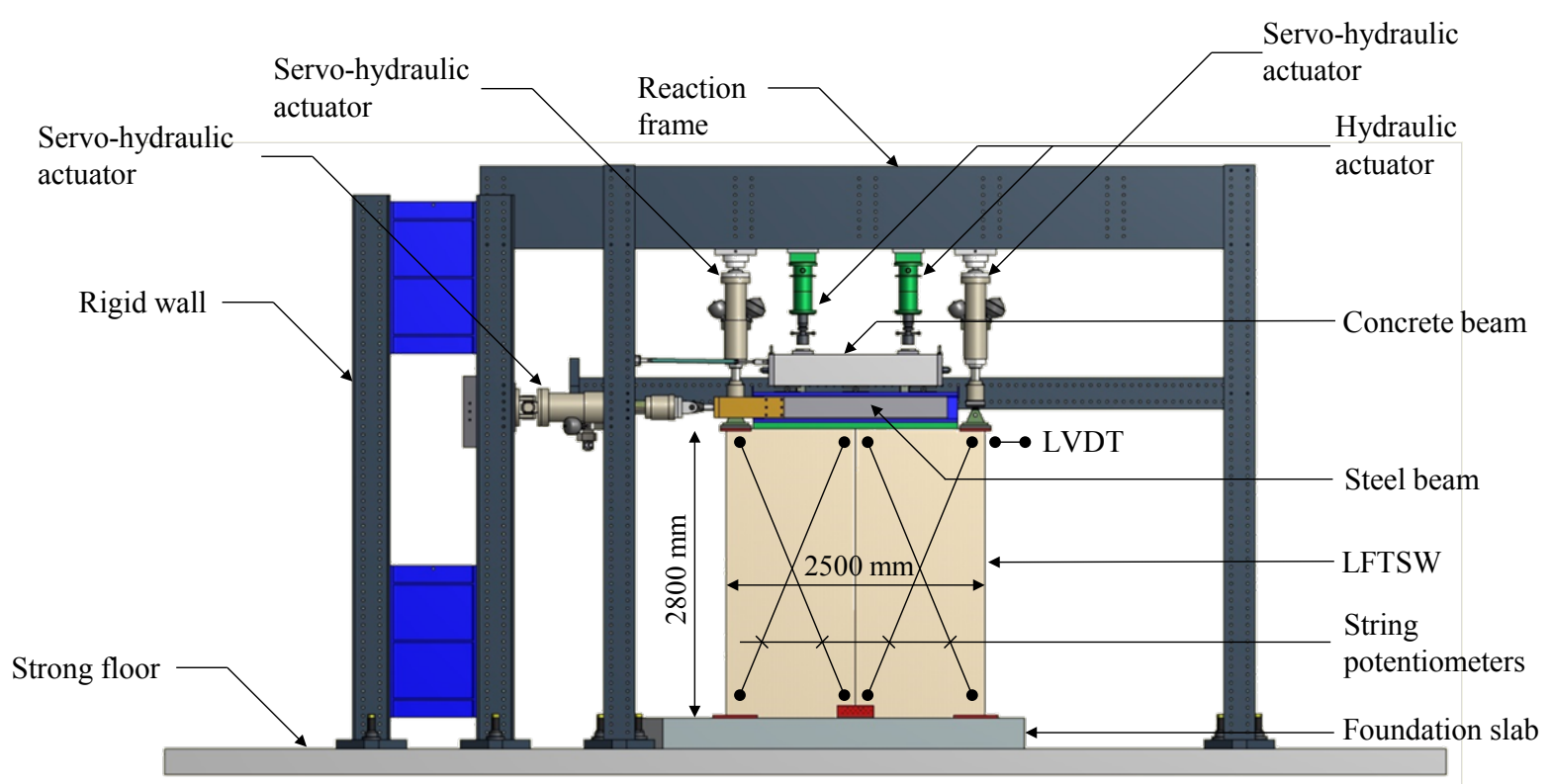

Fig. 9 Test setup.

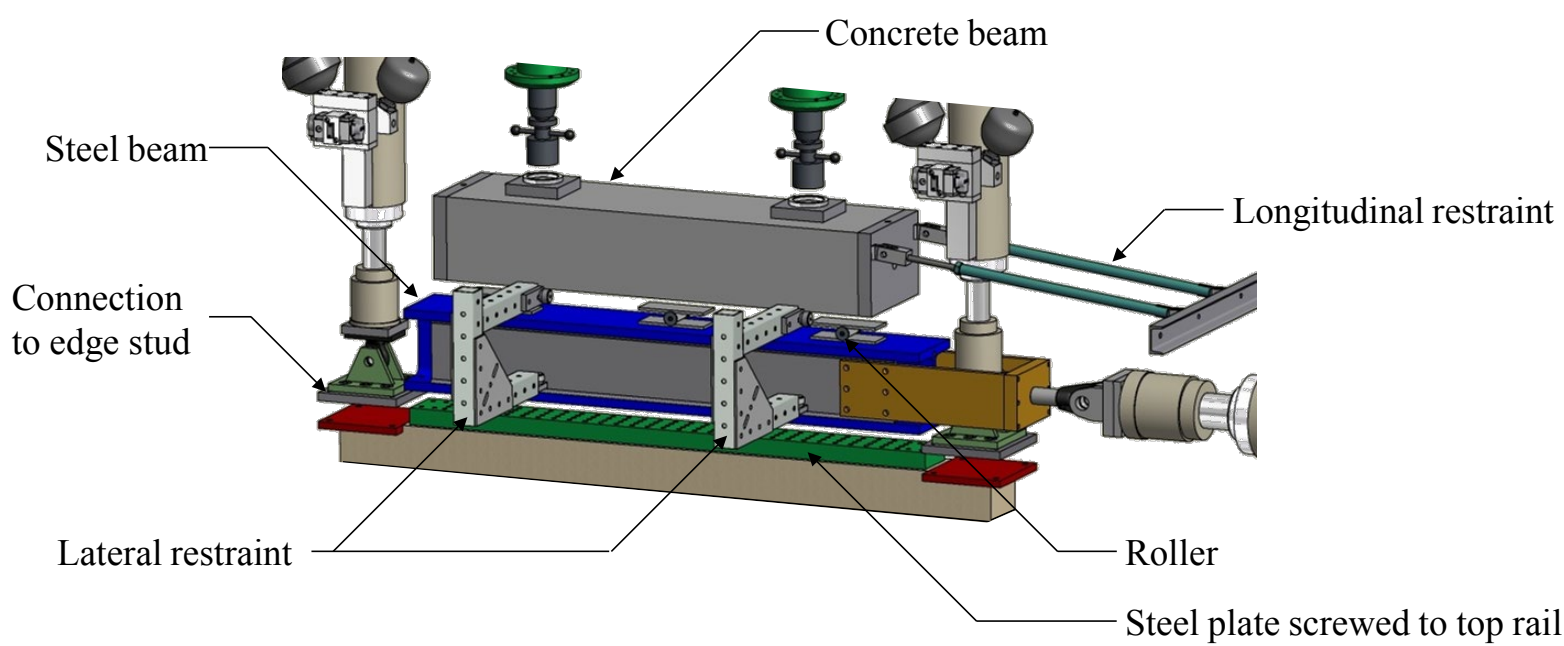

3 Fig. 10 Detailed view of transfer of forces to the LFTSW specimen.

5 The LFTSW was directly anchored to the concrete foundation. The steel plates of the bottom

6 anchorages of the wall were fastened to the anchor bolts embedded in the foundation. Transfer

7 of lateral load to the top of the wall was realized by means of a steel plate screwed to the top

8 rail of the LFTSW using 120 self-tapping screws with a diameter $10 \mathrm{~mm}$ and a length of

$9180 \mathrm{~mm}$ providing a stiff connection. A steel beam composed of an IPE 300 and two steel 
1 plates longitudinally welded to the profile flanges on both sides, providing space for the lateral

2 restraints, was then assembled to the top of the steel plate. The steel beam was connected

3 horizontally to the servo-hydraulic actuator using a set of steel plates. The steel beam

4 represented the floor slab in a real building. A concrete beam was placed on top of the steel

5 beam via three steel rollers allowing for transferring the vertical load of the hydraulic cylinders

6 to the steel beam without constraining the horizontal movement of the wall during the

7 experiments.

\section{$8 \quad$ 4.2.1 Measurements}

9 The force and displacement of all actuators and hydraulic cylinders were measured during the

10 test. A displacement transducer was installed horizontally at the top corner of the wall

11 measuring the horizontal displacement of the framing. Besides that, two string potentiometers

12 were installed on each sheathing panel on one side of the wall measuring the diagonal

13 deformations of the panels (Fig. 9). On the opposite side of the wall, a 3D digital image

14 correlation (DIC) technique was implemented to measure the full-field displacement of the

15 shear wall. The two cameras of the system were triggered by the Digital 3-Channel Control

16 System in various increments of loading.

\section{$17 \quad$ 4.2.2 Test execution}

18 The monotonic testing was a prerequisite for cyclic tests to gain information about the

19 mechanical properties and the load and displacement capacity of the wall. In the failure tests,

20 the vertical loads were applied first and subsequently the lateral load and bending moment

21 were applied according to the desired loading protocol until failure. The monotonic loading

22 protocol is shown in Fig. 11. According to ISO standard 21581 [12], failure of a specimen is

23 reached when there is $20 \%$ degradation in the shear resistance of the wall. In the HV-WOB 
1 test, however, the test was stopped earlier at about 15\% degradation because of reaching the

2 maximum stroke limit of the horizontal actuator.

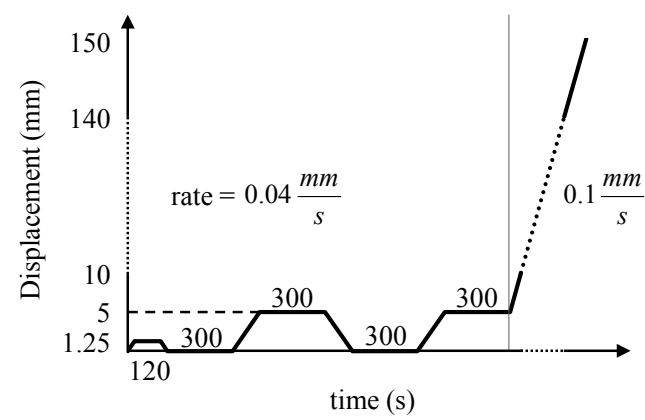

3 Fig. 11 Protocol of monotonic horizontal loading according to ISO standard 21581 [12].

\section{$5 \quad 5 \quad$ Test results and discussion}

\section{$6 \quad 5.1$ General behavior and damage pattern}

7 The load-displacement behavior of the walls, given by the horizontal servo-hydraulic actuator,

8 is compared in Fig. 12 for various loading conditions. The test LV-WOB with a low vertical

9 load and without bending moment is considered as the reference for explaining the general

10 response of the investigated LFTSWs. A generally similar behavior was observed in all

11 specimens. The load-displacement was nonlinear from the very beginning of lateral loading. It

12 was due to the higher shear deformation applied to the staples far from the center of rotation of

13 the sheathing panels, which was initially located close to the shear connector. The edge studs

14 deformed like a cantilever with an approximately zero rotation at their bottom due to the

15 comparatively rigid connection with the foundation. The top rail followed the horizontal

16 displacement of the edge studs and not their rotation because of its pin connection to the edge

17 studs. 


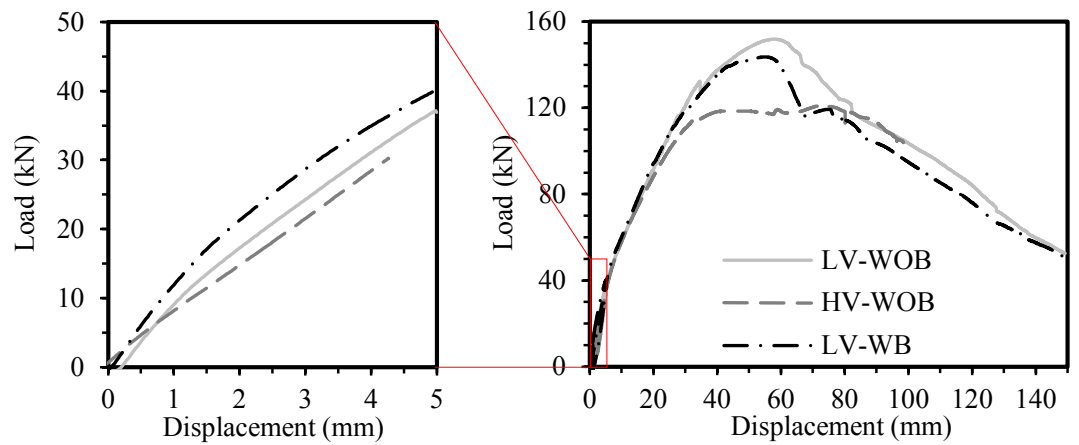

1 Fig. 12 Comparison of load-displacement behavior of the walls: full graphs (right) and detailed

2 view of the initial loading phase (left).

4 By increasing the lateral displacement, the slope of the load-displacement curve decreased

5 because of the reduction in the shear stiffness of the staples (Fig. 6b). The degradation of

6 stiffness continued until the walls reached their maximum shear resistance.

7 Before reaching the peak, a higher stiffness was observed in the tests LV-WOB and LV-WB.

8 This can be justified by taking into account the constructional detail difference between these

9 samples and the one in the test HV-WOB. As can be seen in Fig. 13, in the construction of the

10 specimens, a gap was formed between the sheathing panel and the steel anchorage plates of the

11 framing. By applying the lateral load, the rotation of the sheathing panel resulted in gap closure

12 and, consequently, contact between the sheathing panel and the steel anchorage. Therefore, the

13 rotation of the sheathing panel was restrained by the steel anchorage resulting in a higher

14 stiffness. The initial gap was significantly larger in the specimen HV-WOB, about $10 \mathrm{~mm}$, than

15 in the other two specimens. Therefore, the contact of the sheathing panel and the steel

16 anchorages occurred at a higher displacement (approximately $58 \mathrm{~mm}$ ). As a result, a lower

17 stiffness was observed in this test than the other two. 

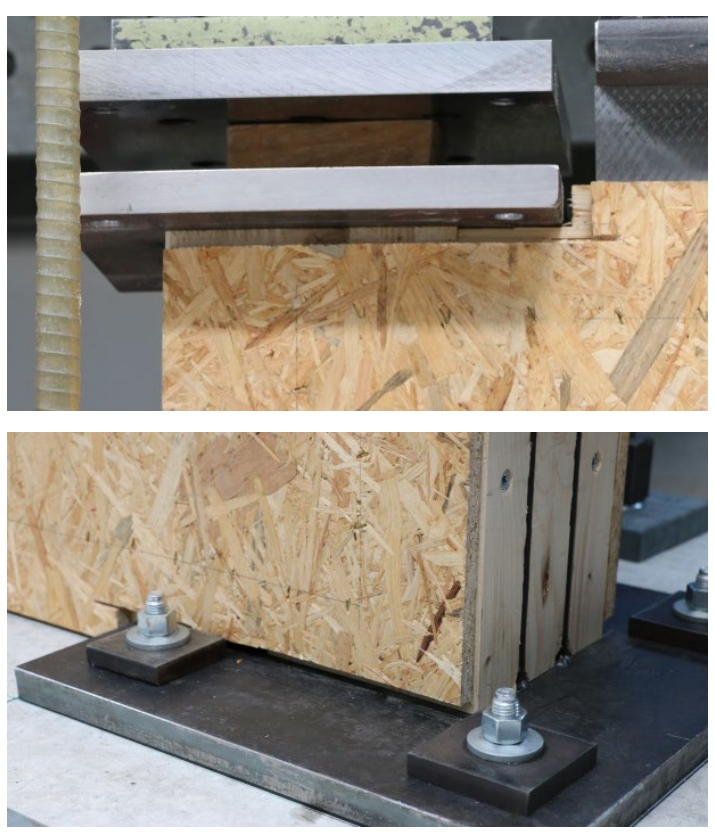

(a)
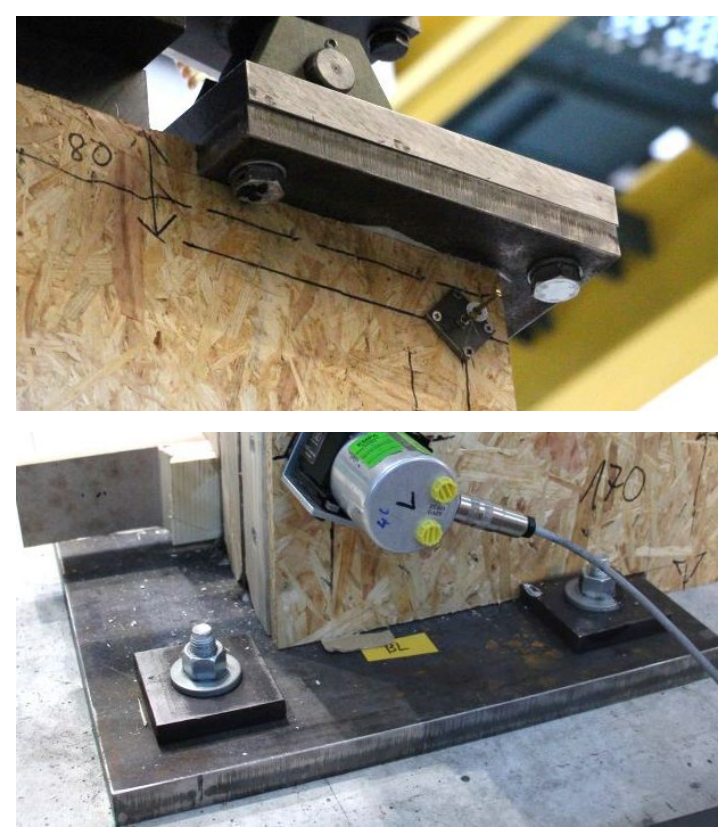

(b)

1 Fig. 13 Difference in the constructional details of sheathing panels forming a gap between the

2 sheathing panel and the steel anchorage plate: (a) a large gap in test HV-WOB and (b) a small 3 gap in test LV-WOB.

5 Due to the contact of the sheathing panel and the steel plates, local buckling occurred in the

6 sheathing panel that resulted in a drop in the shear resistance in the specimen LV-WOB. This

7 drop can be observed in Fig. 12a at a horizontal displacement of $35 \mathrm{~mm}$.

8 The maximum shear resistance of the walls was determined by the shear strength of the staples.

9 Increasing the applied displacement, a relatively high deformation was demanded from the

10 staples, especially from those located further away from the rotation center of panels, resulting

11 in the strength degradation of the stapled connections. Staples subjected to a high deformation

12 demand were increasingly pulled out. This could also be detected in the out-of-plane

13 displacement of the sheathing panels measured by means of the DIC system, see Fig. 14a-b. 


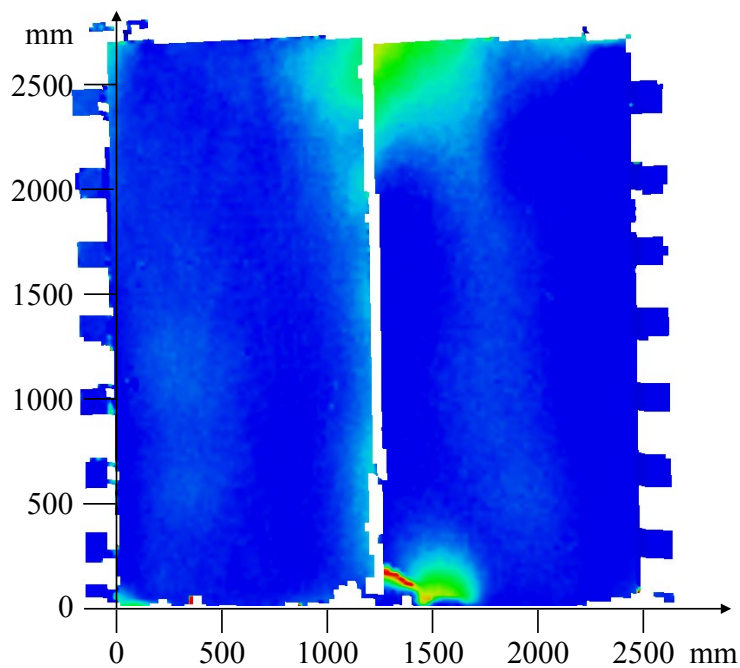

(a)

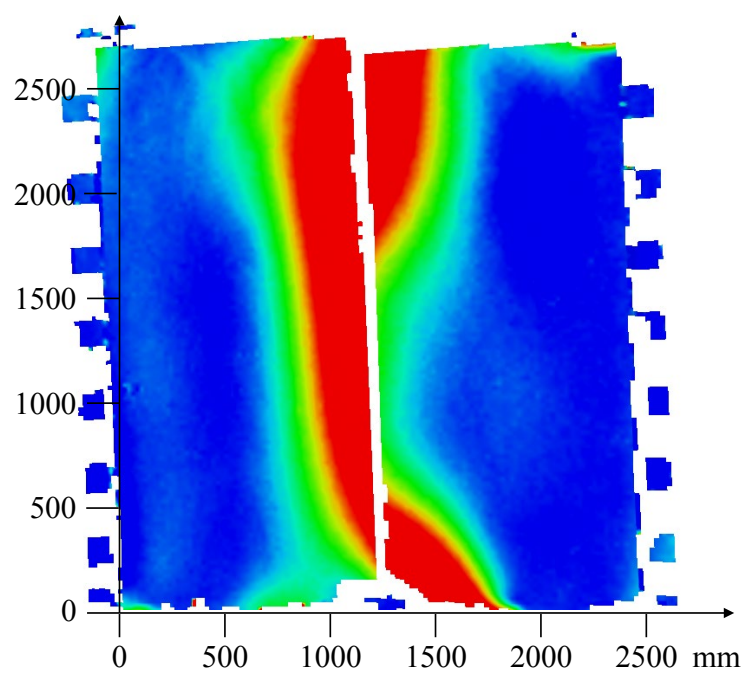

(b)

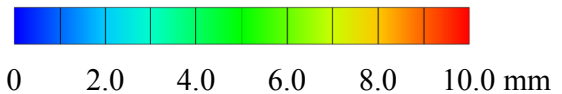

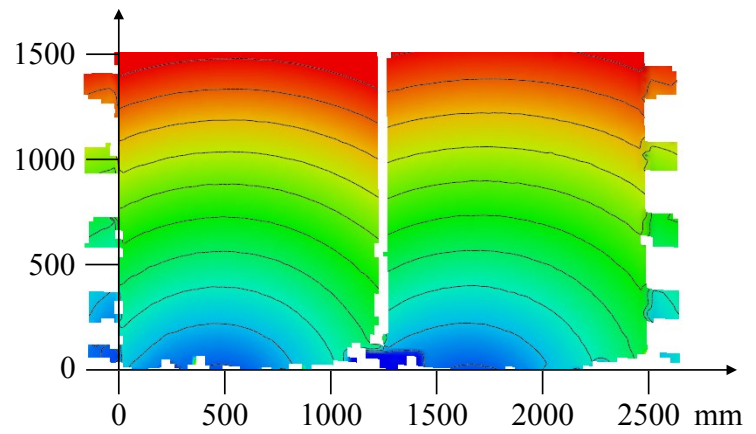

(c)

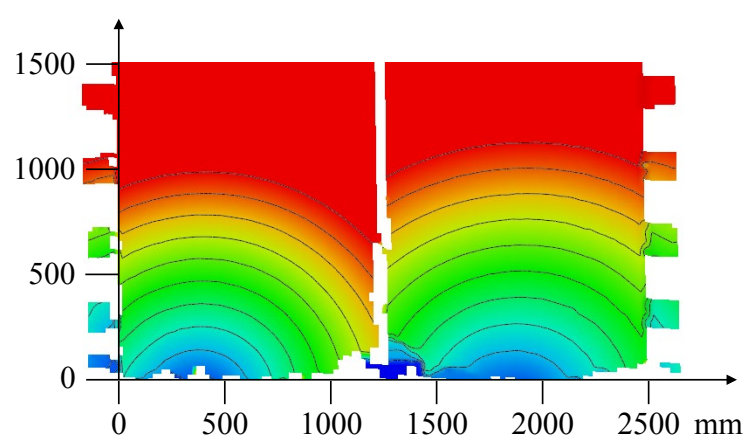

(d)

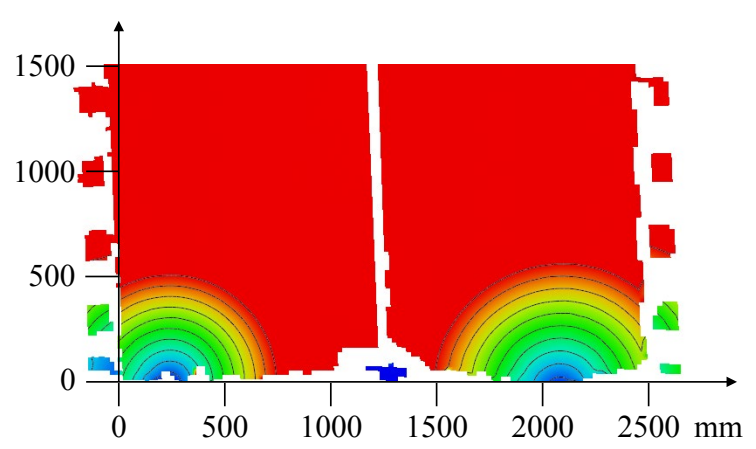

(e)

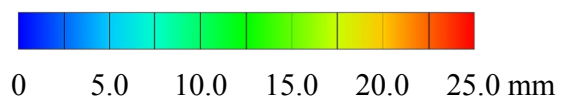

1 Fig. 14 Out-of-plane deformation of the sheathing panels (a) right after buckling at shear 2 connector and (b) at maximum applied displacement and in-plane center of rotation of 3 sheathing panels at (c) maximum shear resistance, (d) after buckling failure of the panel close 4 to shear connector, (e) and at maximum applied displacement in test LV-WOB.

6 With increasing horizontal displacement, the stiffness of the connection between the sheathing

7 panels and the shear connector was reduced because of increasing embedment of the nails in

8 the sheathing panel. This slightly moved the center of rotation of the sheathing panels away

9 from the shear connector. A marked movement of the center of rotation happened when a local 
1 damage occurred in the sheathing panel at the shear connector, which was due to buckling and

2 crushing of the sheathing panel in compression and tearing off of the panels from the frame,

3 Fig. 14c-e. The sudden drop of the shear force in the post-peak range of the load-displacement

4 curve, visible in Fig. 12a, was due to this buckling. Since the sheathing panels were stapled to

5 the intermediate studs, no global buckling was observed.

6 Except for the sudden drop explained above, in all tests a stable and gradual degradation of

7 shear resistance was observed in the post-peak range which reflects a well-known behavior of

8 LFTSW having numerous staples ([34], [35]). Various damages of the wall members are

9 shown in Fig. 15.

10 After the experiment the panels were removed and the state of damage of the framing members

11 was investigated. It was observed that, besides partial embedment of the dowels in the

12 anchorage zones, the framing members did not undergo damage and remained almost intact. A

13 separation was observed between the top rail and the edge stud (Fig. 15e). This shows that the

14 pin connection between them with two screws, used only for construction reasons during

15 prefabrication, has insufficient axial stiffness and strength to tie the top rail and the edge studs

16 together.

17

18

19

20 


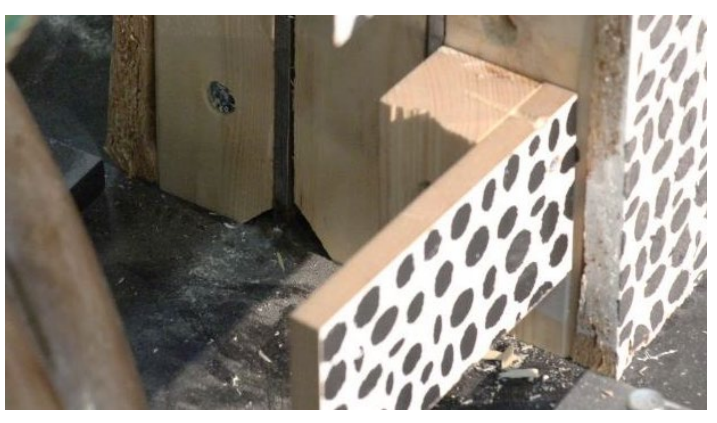

(a)

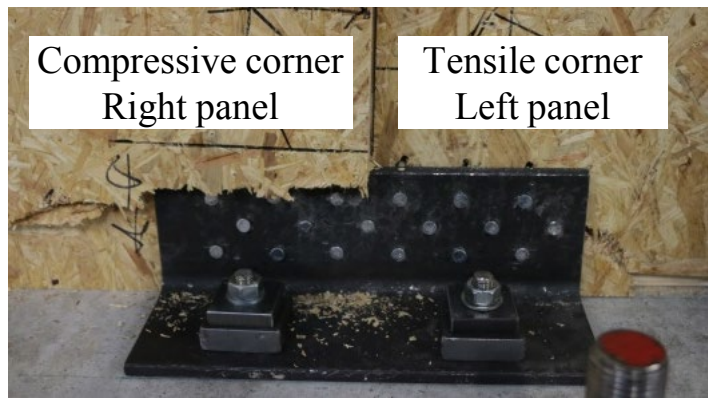

(c)

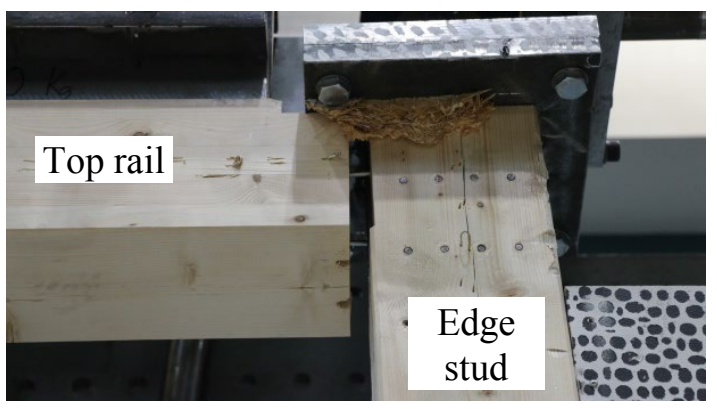

(e)

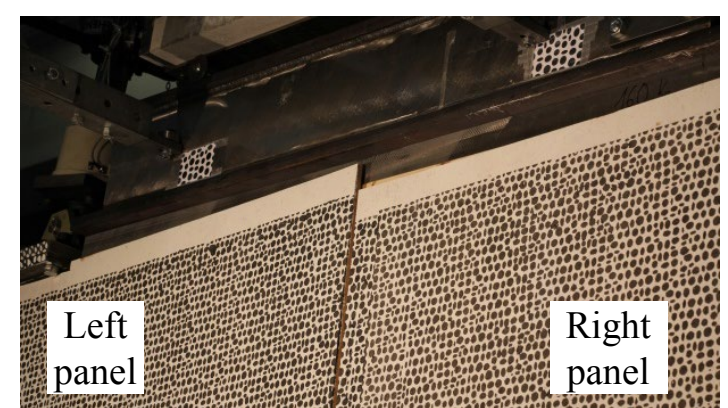

(b)

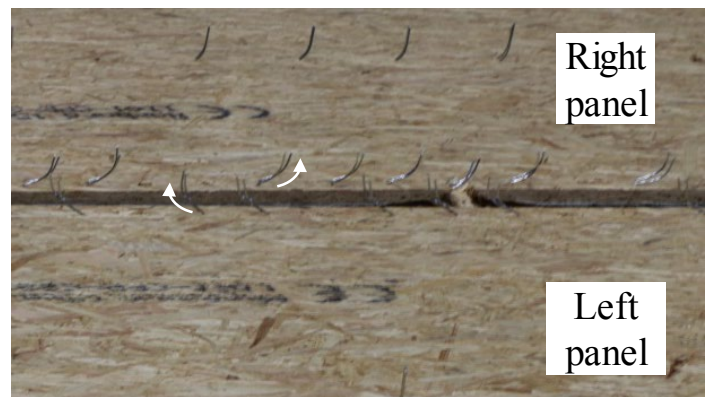

(d)

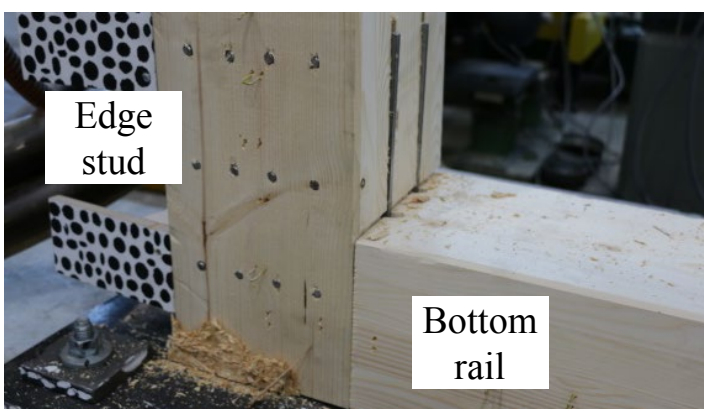

(f)

Fig. 15 (a) Local buckling of sheathing panels at the bottom corner, (b) relative displacement of sheathing panels, (c) buckling-crushing of sheathing panels close to the shear connector, (d) residual plastic deformation of staples, (e) separation of top rail from edge stud and (f) deformation in framing members at the location of anchorage.

The main test results are summarized in Table 2 in terms of maximum shear resistance,

ultimate displacement, and shear stiffness. Since the behavior of LFTSWs is nonlinear from the very beginning of lateral loading, the shear stiffness was evaluated at different levels of displacement namely at the serviceability limit state $(5 \mathrm{~mm})$ and $25 \%$ of it, which can be observed in the loading protocol (Fig. 11). A high scatter was observed in the initial shear stiffness of the walls because of the difference between the initial states of the specimens.

The ultimate displacement is considered similarly in all the methods being equal to the displacement corresponding to a $20 \%$ degradation of the shear resistance. As mentioned earlier, 
1 in the specimen HV-WOB, the test was stopped at a $100 \mathrm{~mm}$ displacement (representing a $15 \%$

2 degradation) because of the stroke limit of servo-hydraulic actuator in the test setup.

3 Table 2: Maximum shear resistance ( $\left.P_{\max }\right)$, ultimate displacement $\left(D_{u}\right)$, and secant stiffness ( $\left.4 \quad K_{\text {sec }}\right)$ for the experimentally investigated LFTSWs.

\begin{tabular}{lcccc}
\hline Test & $\begin{array}{c}P_{\max } \\
(\mathrm{kN})\end{array}$ & $\begin{array}{c}D_{u} \\
(\mathrm{~mm})\end{array}$ & $\begin{array}{c}K_{\text {sec, } 0-1.25 \mathrm{~mm}} \\
(\mathrm{kN} / \mathrm{mm})\end{array}$ & $K_{\text {sec, } 0-1.25 m m}$ \\
\hline LV-WOB & 151.9 & 81.6 & 8.9 & 7.7 \\
HV-WOB & 121.1 & 99.0 & 6.7 & 6.9 \\
LV-WB & 143.6 & 78.1 & 11.6 & 8.1 \\
\hline
\end{tabular}

\section{$5 \quad 5.2$ Effect of vertical load}

6 As seen in Table 2, a marked 20\% decrease in shear resistance was obtained in the test under

7 higher vertical load (HV-WOB). However, this decrease is not exclusively due to the applied

8 vertical load, but also due to the local geometrical difference of the specimens. This can be

9 explained better using Fig. 16a, where the relative vertical displacements at two main corners

10 of the wall are illustrated. Because of the larger existing gap in the test HV-WOB, the relative

11 vertical displacement of the sheathing from the framing is much larger in the test under high

12 vertical load than in the reference test (LV-WOB). Therefore, the demand on the staples at

13 these corners was significantly higher under the high concentrated vertical load on the edge

14 studs. Similarly, at the location of the shear connector, shown in Fig. 16b, a larger downward

15 vertical deformation was observed in the test HV-WOB, which is due to the higher

16 displacement demand on the staples located in the vicinity of the shear connectors. 


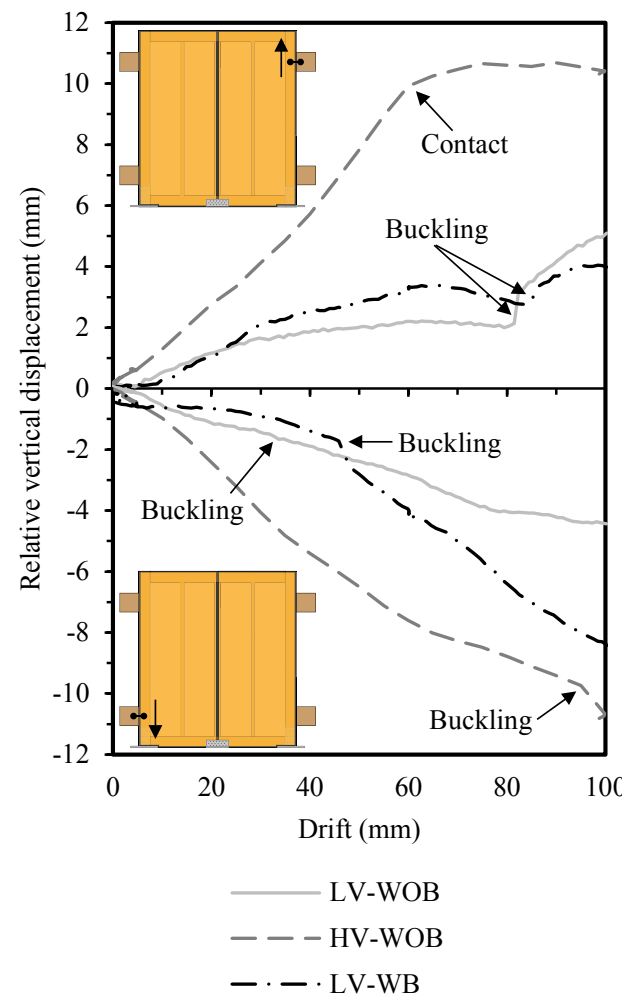

(a)

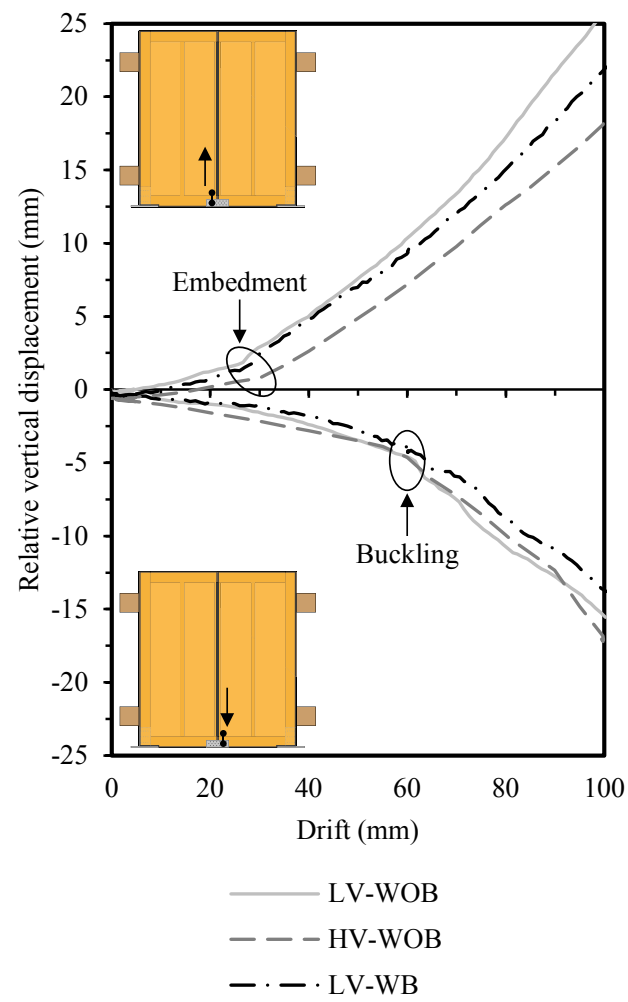

(b)

1 Fig. 16 Vertical displacement of sheathing panel relative to (a) framing and (b) shear

2 connector.

3 In order to estimate the effect of vertical load without taking into account the mentioned

4 differences in constructional detailing, the developed FE model was used. As shown in Fig. 17,

5 the results of the numerical investigations also confirm the reduction in shear resistance of the

6 walls under higher vertical load, although the reduction is smaller (about 3.5\%) compared with

7 the experimental results being about $20 \%$.
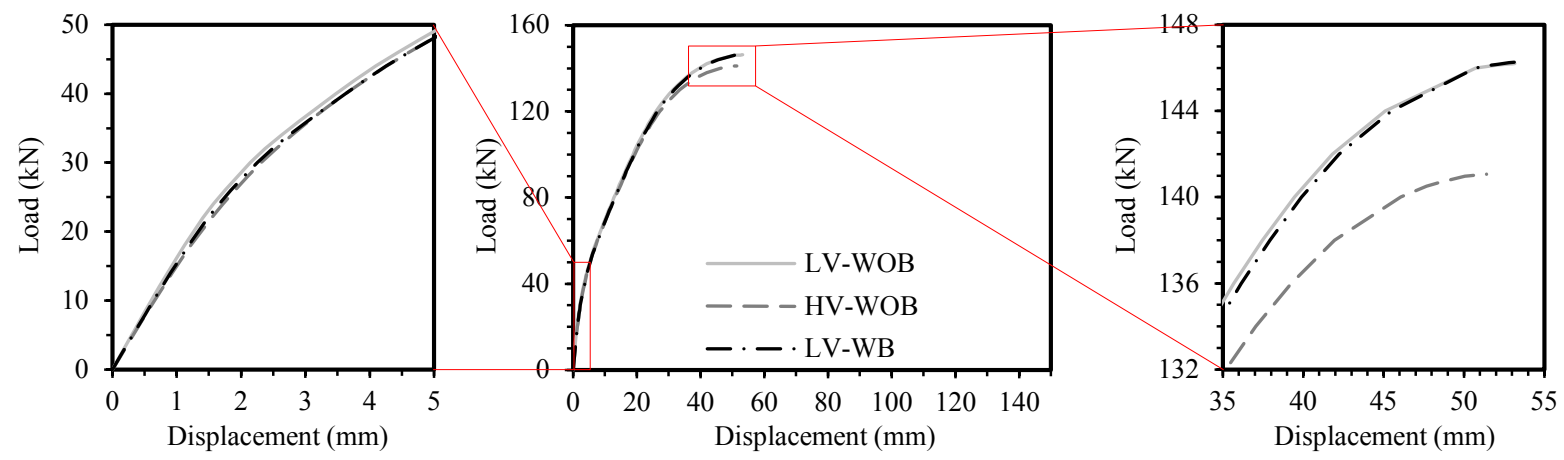

8 Fig. 17 Comparison of load-displacement behavior of the walls using the FE model: full

9 graphs (center) and detailed view of the initial part (left) and of the part close to the maximum 10 load (right). 
1 Some test results reported in the literature show an enhancement of shear resistance with

2 increasing vertical load when timber walls are not fully anchored to the foundation ([13]). But

3 there are others where no significant influence of vertical load on the shear resistance of the

4 timber shear walls was found([14]). Germano et al [15] obtained a marginally lower shear

5 resistance in walls under higher vertical load where the uplift was restrained. In our study, in

6 the investigated shear walls, the uplift of the wall was blocked by the strong anchorages.

7 Hence, the results correspond well to the established walls with restrained uplift.

8 In the LFTSWs investigated in this study, the sheathing panels contributed in carrying vertical

9 loads even when the loads were directly introduced to the edge studs. This was because the

10 vertical displacement of the panels was constrained by the shear connector. Therefore, a

11 fraction of the vertical load applied to the edge studs was resisted by the stapled connection

12 between sheathing panels and edge studs and transferred to the foundation through the

13 sheathing panels and, subsequently, the shear connector. It was also observed in the results of

14 the FE calculations that the shear stiffness of the wall under high vertical stress is smaller

15 because of the deformation of staples under the high concentrated vertical loads and the

16 consequent reduction of their stiffness. This can be seen in the secant stiffness $K_{\text {sec }}$ in the

17 serviceability limit state in Table 2.

18 It must be noted that in the FE model the deformation of sheathing panels at the shear

19 connector (Fig. 15c) as well as the separation of the top rail from the edge stud (Fig. 15e) are

20 not taken into account. This is equivalent to assuming a zero relative displacement at the shear

21 connector, seen in Fig. 16b, which is valid only for low displacements. It is expected that if

22 these deformations were considered in the model, the estimated shear stiffness would decrease

23 due to the reduced constraint of the sheathing panels.

24 In terms of displacement capacity, even though a similar behavior was observed in both

25 specimens after $80 \mathrm{~mm}$ displacement, Table 2 expresses a much higher displacement capacity 
1 (about 21\% higher) in the wall under high vertical load that than in the reference wall.

2 Apparently, this is due to the definition of ultimate displacement, corresponding to a $20 \%$ drop

3 in the shear resistance [12]. As explained earlier, according to the numerical investigations

4 (Fig. 17), the difference in shear resistance is not as significant and therefore, a lower

5 difference in ultimate displacement is expected. Moreover, it can be noted that a target

6 displacement of $100 \mathrm{~mm}$ was satisfactorily reached in both walls without having a brittle

7 failure.

\section{$8 \quad 5.3$ Effect of bending moment}

9 In terms of constructional details of the sheathing panels, the specimen tested by applying a

10 bending moment (LV-WB) was similar to that in the reference test. Nevertheless, local

11 buckling of the sheathing panels occurred at different load levels (Fig. 16a). Therefore, to

12 explain the difference between the behaviors of the two walls, it is necessary to apply the

13 developed FE model.

14 Experimental results showed a marginal 5\% decrease in the maximum shear resistance of the

15 wall under bending moment (Fig. 12 and Table 2). Similar to the test under high vertical load,

16 however, the FE model resulted in a much smaller difference between the maximum shear

17 resistances of the two walls (Fig. 17). Therefore, it can be concluded that the bending moment

18 was not highly influential on the maximum shear resistance of the LFTSWs investigated in this

19 study. From further parameter studies using the FE model, it was found that applying higher

20 bending moments decreases the shear resistance of the investigated LFTSWs wall only to a

21 small extent, especially when the axial stiffness of the framing members is considerably high.

22 In this case, the axial strain in the framing members remains limited and therefore the relative

23 deformation of sheathing panels and framing members is not highly influenced by the applied

24 bending moment. 
1 According to the experimental results, the initial shear stiffness in the test LV-WB was higher

2 than that in the test LV-WOB, which is assumed to be due to the difference in the initial state

3 of the walls. The results of the numerical investigations, illustrated in Fig. 17, show a lower

4 initial shear stiffness in the wall under bending moment when the constructional details are

5 assumed identical. Similar to the influence of vertical load, this is attributed to the deformation

6 of staples under the applied bending moment.

7 As can be seen in Fig. 12 and Table 2, the difference between the ultimate displacements of the

8 walls tested with and without bending moment is negligible. Both wall specimens showed a

9 similar smooth degradation in the post-peak behavior after buckling occurred in the sheathing

10 panels close to the shear connector. Hence, the displacement capacity of both walls is supposed

11 to be similar.

\section{$12 \quad 5.4$ Remarks on stiffness and ductility evaluation methods}

13 The configuration of established LFTSWs in the literature is different form the investigated

14 ones in this study (see the introduction and Fig. 1). In the established configuration, the hold-

15 downs play an important role in the shear stiffness and resistance of timber shear walls by

16 blocking the uplift of the wall. Moreover, in addition to the fasteners between sheathing and

17 framing members, the ductility of the system is expected to be provided by the hold-downs. In

18 the investigated configuration, however, the strong anchorages block the vertical displacement

19 of the edge studs and therefore the ductility is provided mainly by the staples.

20 Shear stiffness of the walls calculated at various displacements and load levels using methods

21 are compared in Fig. 18. The solid horizontal line shows the stiffness evaluation of established

22 walls according to the analytical model expressed in equations (1)-(4). The horizontal dashed

23 lines stand for the stiffness evaluation using the FE model, in which a linear stiffness of $K_{\text {ser }}$

24 was assigned to the staples. As seen in Fig. 18, at a very low level of displacement (1.25 mm, 
1 being equal to $25 \%$ of the serviceability limit) a high scatter is observed in the experimental

2 results that is due to the different initial state of the wall samples. A more consistent stiffness

3 estimation is obtained when addressing the serviceability limit state ( $5 \mathrm{~mm}$ displacement) as

4 well as in the force limits between $10 \%$ and $40 \%$ of maximum shear resistance. Stiffness

5 assessment using equations (1)-(4) is seen to be valid for established walls, but applying those

6 equations to the investigated walls underestimates the stiffness significantly. In the force-based

7 seismic design of timber buildings, an underestimation of stiffness of LFTSWs results in an

8 overestimation of fundamental period of the building that could lead to an unsafe estimation of

9 seismic forces. This fact emphasizes the importance of correctly estimating the stiffness of

10 staples as well as using a proper method for estimating the shear stiffness of LFTSWs. The

11 developed FE model allows for a better estimation of the stiffness of LFTSWs. Using the FE

12 model as the reference, the analytical models can be modified by considering realistic

13 boundary conditions and constraints for framing members and sheathing panels. In case of

14 applying the current analytical equations, the constructional details and boundary conditions

15 should follow certain guidelines (e.g. APA) that the validity and suitability of equations are

16 endorsed. Otherwise, it is recommended to estimate the design seismic force conservatively

17 based on the plateau of the design spectrum.

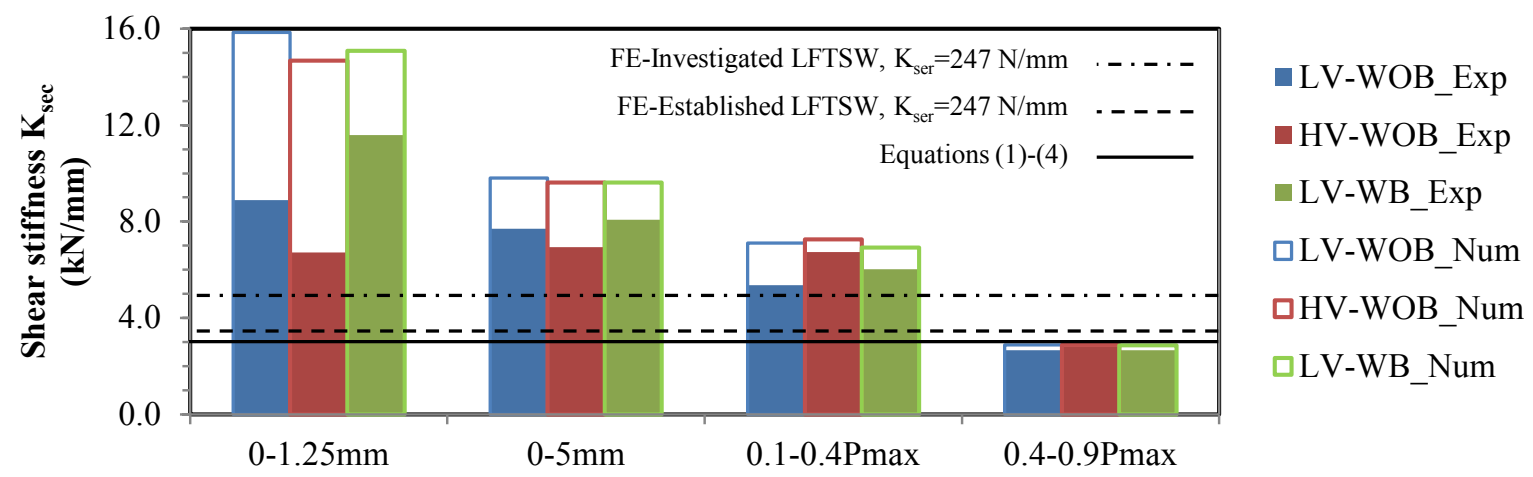

18 Fig. 18 Shear stiffness $\left(K_{\mathrm{sec}}\right)$ of investigated LFTSWs obtained by experimental, analytical,

19 and numerical (FE) analyses 
1 Several common standards and methods were used for finding the equivalent bilinear load-

2 displacement curve and corresponding seismic design parameters ([11], [36], and [37]). Table

33 shows the stiffness and ductility factor estimated using the aforementioned methods. It can be

4 seen that in terms of shear stiffness and ductility the American and European standards lead to

5 similar results. The method proposed by Kobayashi et al. [37] underestimates the shear

6 stiffness and ductility compared with the other two methods. Comparing our results with those

7 from Seim et al. [1] in their research program on established LFTSWs with OSB sheathing

8 panels and nail fasteners, a higher shear stiffness and almost similar ductility factor were

9 obtained.

10 Table 3: Secant stiffness $\left(K_{\mathrm{sec}}\right)$ and ductility factor $(\mu)$ for the experimentally investigated

11 LFTSWs.

\begin{tabular}{|c|c|c|c|c|c|c|}
\hline \multirow[t]{2}{*}{ Test } & \multicolumn{2}{|c|}{ ASTM E2126 [11] } & \multicolumn{2}{|c|}{ EN $12512[36]$} & \multicolumn{2}{|c|}{ Kobayashi et al. [37] } \\
\hline & $\begin{array}{c}K_{\text {sec }, 0-0.4} \\
(\mathrm{kN} / \mathrm{mm})\end{array}$ & $\begin{array}{l}\mu \\
(-)\end{array}$ & $\begin{array}{l}K_{\mathrm{sec}, 0.1-0.4} \\
(\mathrm{kN} / \mathrm{mm})\end{array}$ & $\begin{array}{l}\mu \\
(-)\end{array}$ & $\begin{array}{c}K_{\mathrm{sec}} \\
(\mathrm{kN} / \mathrm{mm})\end{array}$ & $\begin{array}{l}\mu \\
(-)\end{array}$ \\
\hline LV-WOB & 5.9 & 3.6 & 5.6 & 3.7 & 5.0 & 3.0 \\
\hline HV-WOB & 6.7 & 6.0 & 6.7 & 7.2 & 6.2 & 5.4 \\
\hline LV-WB & 6.7 & 4.2 & 6.3 & 4.3 & 5.6 & 3.4 \\
\hline
\end{tabular}

12

13 Regarding Table 3, in terms of the shear stiffness $K_{\text {sec }}$ for force limits between $10 \%$ and $40 \%$

14 of the maximum shear resistance, a higher value was estimated for the wall under high vertical

15 load. This is in contradiction with the results shown in Table 2 estimating the shear stiffness

16 based on a certain displacement (including serviceability limit) applied to the walls. The reason

17 is that in these methods the shear stiffness is defined based on the maximum shear resistance. It

18 is obvious that because of the lower maximum shear resistance of the wall under high vertical

19 load, a lower value of shear force, equivalent to e.g. $40 \%$ of the maximum shear resistance,

20 should be taken into account for stiffness evaluation. Owing to the naturally nonlinear behavior 
1 of timber shear walls, consideration of a lower shear force level results in a relatively lower

2 corresponding displacement that consequently leads to a higher stiffness evaluation.

3 Again, regarding Table 3, the ductility factor $\mu$ is estimated to be higher in the wall under high

4 vertical load. This obviously goes in line with the higher ultimate displacement evaluated in

5 that wall as well as the lower yield displacement as a result of higher stiffness evaluation. Since

6 the higher ultimate displacement is also to be attributed to the difference in the constructional

7 details of the sheathing panels, the higher ductility in the test HV-WOB cannot be exclusively

8 assigned to the high vertical load. Furthermore, even though the ductility is higher in the test

9 HV-WOB, the other tests showed a ductile behavior when looking at the gradual degradation

10 in the post-peak behavior of load-displacement diagram (Fig. 12).

\section{Conclusions}

12 The paper investigates the behavior of OSB sheathed light-frame timber shear walls with

13 strong anchorage subjected to vertical load and bending moment in addition to the monotonic

14 lateral load occurring when LFTSWs are used as the lateral load resisting system in multi-story

15 buildings. Based on this study the following conclusions can be drawn:

16 Due to the assumption of rotation of the sheathing panels about their centroid as well as

17 the rotation of edge studs about their bottom existing analytical methods underestimate

18 the shear stiffness of LFTSWs with strong anchorage. Additional shear connectors

19 constrain the translation of the corresponding corner of sheathing panels and lead to a

20 shift of the center of rotation of the sheathing panels. As a result, the relative

21 displacement of sheathing panel and framing members change and, therefore, a

22 different deformation is demanded from the staples. The analytical models for stiffness 
evaluation can be modified by considering realistic boundary conditions for framing members and sheathing panels.

- Using the developed FE model, suitable for both established and investigated LFTSWs, a substantial increase in shear resistance and shear stiffness was found in the LFTSWs with strong anchorages compared with LFTSWs of established configuration. As a result, timber buildings consisting of LFTSWs of the type investigated in this study experience lower deflections under wind load in the serviceability state.

- In the monotonic racking tests, the investigated LFTSWs showed a ductile behavior where the staples were the main provider of ductility to the system. Due to appropriate design, no global buckling was observed in the sheathing panels. The strong framing members remained almost intact even after applying a 5\% drift to the walls. A gradual post-peak behavior was observed in the load-displacement of the walls until the maximum applied drift.

- The vertical load and bending moment were found to marginally decrease the shear resistance and stiffness of the investigated LFTSWs. This is in agreement with results published in the literature for fully anchored LFTSWs in which the uplift had been restrained. The observed decrease is in fact due to the higher deformation demand to the staples because of both vertical load and bending moment. The ductility was found to be higher in the test under high vertical load. However, this is not exclusively due to the higher vertical load but also due to the difference in the constructional details of the sheathing panels, which directly affects the shear resistance of the walls and, consequently, the evaluated ultimate displacement.

- Constructional details, specifically of the sheathing panels at the location of anchorages, were found to be highly influential on the shear resistance of the investigated LFTSWs. Therefore, the corresponding guidelines for execution of 
LFTSWs (e.g. having sufficient spacing between sheathing panels) shall be respected and the executive plans for construction shall be precisely followed.

- For execution purposes, the connection between the edge studs and top rail consists of only two screws. Improving the axial stiffness of this connection, for instance by using more screws, can enhance the shear stiffness of LFTSWs resulting in a lower lateral displacement of LFTSWs in the serviceability state under wind loads.

\section{$7 \quad 7$ Acknowledgement}

This study was supported by the Swiss National Science Foundation SNSF (National Research

9 Program 66 Resource Wood, Project 406640-136900).

\section{References}

11 [1] Seim W, Hummel J, Vogt T. Earthquake design of timber structures - Remarks on force12 based design procedures for different wall systems. Engineering Structures. 2014;76:124-37.

13 [2] Yeh B, Williamson T, Keith E. Combined shear and wind uplift resistance of wood 14 structural panel shearwalls. In: Griffis L, Helwig T, Waggoner M, Hoit M, editors. Structures 15 Congress 2009. Austin, Texas, United States, 2009, 1662-72.

16 [3] Dujic B, Aicher S, Zarnic R. Testing of wooden wall panels applying realistic boundary

17 conditions. Proceedings of the 9th World Conference on Timber Engineering. Portland,

18 Oregon, United States, 2006, p. 1186-93.

19 [4] Skaggs T, Yeh B, Lam F. Full-scale shear wall tests for force transfer around openings.

20 Meeting 43 of the Working Commission W18-Timber structures, CIB. St. Andrews, Canada, 21 2010, Paper CIB-W18/43-15-3.

22 [5] Yasumura M. Influence of the boundary conditions on the racking strength of shear walls 23 with an opening. Meeting 43 of the Working Commission W18-Timber structures, CIB.

24 Nelson, New Zealand, 2010, Paper CIB-W18/43-15-1.

25 [6] Yeh B, Keith E, Skaggs T. Optimized anchor-bolt spacing for structural panel shearwalls. 26 Meeting 43 of the Working Commission W18-Timber structures, CIB. Nelson, New Zealand, 27 2010, Paper CIB-W18/43-15-4.

28 [7] Dolan JD, Toothman AJ. Comparison of monotonic and cyclic performance of light-frame 29 shear walls. Meeting 36 of the Working Commission W18-Timber structures, CIB. Colorado, 30 United States, 2003, Paper CIB-W18/36-15-7. 
1 [8] Lam F, Jossen D, Gu J, Yamaguchi N, Prion HGL. Effect of test configuration and 2 protocols on the performance of shear walls. Meeting 36 of the Working Commission W18-

3 Timber structures, CIB. Colorado, United States, 2003, Paper CIB-W18/36-15-6.

4 [9] Schädle P, Blass HJ. Influence of different standards on the determination of eartquake 5 properties of timber shear wall systems. Meeting 43 of the Working Commission W18-Timber 6 structures, CIB. Nelson, New Zealand, 2010, Paper CIB-W18/43-15-2.

7 [10] Lam F, Filiatrault A, Kawai N, Nakajima S, Yamaguchi N. Performance of timber 8 buildings under seismic load. Part I: experimental studies. Prog Struct Engng Mater.

$9 \quad 2002 ; 4: 276-85$.

10 [11] ASTM E2126 - 11. Standard Test Methods for Cyclic (Reversed) Load Test for Shear 11 Resistance of Vertical Elements of the Lateral Force Resisting Systems for Buildings. West 12 Conshohocken, PA, United States: ASTM International; 2011.

13 [12] ISO 21581. Timber structures - Static and cyclic lateral load test methods for shear walls. 14 Geneva, Switzerland: International Organization for Standardization (ISO); 2010.

15 [13] Dean P, Shenton H. Experimental investigation of the effect of vertical load on the 16 capacity of wood shear walls. J Struct Eng. 2005;131:1104-13.

17 [14] Payeur M, Salenikovich A, Munoz W. Influence of vertical loads on lateral resistance and 18 deflections of light frame shear walls. Meeting 44 of the Working Commission W18-Timber 19 structures, CIB. Alghero, Italy, 2011, Paper CIB-W18/44-15-2.

20 [15] Germano F, Metelli G, Giuriani E. Experimental results on the role of sheathing-to-frame and base connections of a European timber framed shear wall. Construction and Building Materials. 2015;80:315-28.

[16] EN 14080. Timber structures - Glued laminated timber and glued laminated solid timber Requirements. Brussels, Belgium: European Committee for Standardization (CEN); 2013. [17] EN 300. Oriented Strand Boards (OSB) - Definitions, classification and specifications.

26 Brussels, Belgium: European Committee for Standardization (CEN); 2006.

[18] EN 13986. Wood-based panels for use in construction - Characteristics, evaluation of conformity and marking. Brussels, Belgium: European Committee for Standardization (CEN); 2004.

30 [19] Varoglu E, Karacabeyli E, Stiemer S, Ni C. Midply Wood Shear Wall System: Concept 31 and Performance in Static and Cyclic Testing. J Struct Eng. 2006;132:1417-25.

32 [20] APA - The Engineered Wood Association. Builder Tip: Prevent Buckling with Proper 33 Spacing (Form M300S). Tacoma, Washington, USA2013.

34 [21] EN 1995-1-1. Eurocode 5: Design of timber structures - Part 1-1: General - Common rules 35 and rules for buildings. Brussels, Belgium: European Comittee for Standardization (CEN); 362004.

37 [22] DIN 1052 : 2008. Design of timber structures - General rules and rules for buildings.

38 Berlin, Germany: Deutsches Institut für Normung (DIN); 2008.

39 [23] McCutcheon WJ. Racking Deformations in Wood Shear Walls. Journal of Structural 40 Engineering. 1985;111:257-69.

41 [24] Judd JP, Fonseca FS. Analytical model for sheathing-to-framing connections in wood 42 shear walls and diaphragms. J Struct Eng-Asce. 2005;131:345-52. 
1 [25] Kallsner B, Girhammar UA. Analysis of fully anchored light-frame timber shear walls-

2 elastic model. Mater Struct. 2009;42:301-20.

3 [26] SIA 265:2003. Timber structures. Zurich, Switzerland: Swiss Society of Engineers and

4 Architects; 2003.

5 [27] CSA O86-14. Engineering design in wood. Toronto, Canada: CSA, Canadian Standard

6 Association; 2016.

7 [28] NZS 3603:1993. Timber structures standard. Wellington, New Zealand: Standards New

8 Zealand; 1993.

9 [29] Kessel MH. Tafeln-eine elastische, geometrisch lineare Beschreibung. In: Ehlbeck J,

10 editor. Holzbau Kalender 2003. Karlsruhe: Bruderverlag; 2002. p. 599-632.

11 [30] Folz B, Filiatrault A. Cyclic analysis of wood shear walls. J Struct Eng. 2001;127:433-41.

12 [31] Mohamad R, Bernasconi A. Report on the state of the art of Module 1 "Connections"2015.

13 [32] Folz B, Filiatrault A. CASHEW-Version 1.0: A computer program for cyclic analysis of

14 wood shear walls. Richmond, California: University of California, San Diego; 2000.

15 [33] Steiger R, Feltrin G, Weber F, Nerbano S, Motavalli M. Experimental modal analysis of a

16 multi-storey light-frame timber building. Bulletin of Earthquake Engineering. 2015.

17 [34] Dolan J, Foschi R. Structural Analysis Model for Static Loads on Timber Shear Walls. J

18 Struct Eng. 1991;117:851-61.

19 [35] Seim W, Kramar M, Pazlar T, Vogt T. OSB and GFB As Sheathing Materials for Timber-

20 Framed Shear Walls: Comparative Study of Seismic Resistance. J Struct Eng.

21 2015;142(4):E4015004.

22 [36] EN 12512. Timber structures - Test methods - Cyclic testing of joints made with

23 mechanical fasteners. Brussels, Belgium: European Committee for Standardization (CEN);

242001.

25 [37] Kobayashi K, Yasumura M. Evaluation of plywood sheathed shear walls with screwed

26 joints tested according to ISO 21581. Meeting 44 of the Working Commission W18-Timber

27 structures, CIB. Alghero, Italy, 2011, Paper CIB-W18/44-15-8. 